\title{
EFEITO DA ORIGEM DOS ISOLADOS DO Cucumber mosaic virus (CMV) E DA PRESENÇA DE DOIS POTYVIRUS NA TRANSMISSÃO DO CMV PARA ABOBRINHA DE MOITA POR MEIO DE DUAS ESPÉCIES DE AFÍDEOS.
}

\author{
ZAYAMe VegetTe Pinto
}

\author{
Dissertação apresentada à Escola Superior de \\ Agricultura "Luiz de Queiroz", Universidade de São \\ Paulo, para obtenção do título de Mestre em \\ Agronomia, Área de Concentração: Fitopatologia.
}

P I R A C I C A B A

Estado de São Paulo - Brasil

Dezembro - 2003 


\title{
EFEITO DA ORIGEM DOS ISOLADOS DO Cucumber mosaic virus (CMV) E DA PRESENÇA DE DOIS POTYVIRUS NA TRANSMISSÃO DO CMV PARA ABOBRINHA DE MOITA POR MEIO DE DUAS ESPÉCIES DE AFÍDEOS.
}

\author{
ZAYAMe VegetTe Pinto \\ Engenheiro Agrônomo
}

Orientador: Prof. Dr. JORGE ALBERTO MARQUES REZENDE

Dissertação apresentada à Escola Superior de Agricultura "Luiz de Queiroz", Universidade de São Paulo, para obtenção do título de Mestre em Agronomia, Área de Concentração: Fitopatologia.

P I R A C I C A B A

Estado de São Paulo - Brasil

Dezembro - 2003 


\section{Dados Internacionais de Catalogação na Publicação (CIP)} DIVISÃO DE BIBLIOTECA E DOCUMENTAÇÃO - ESALQ/USP

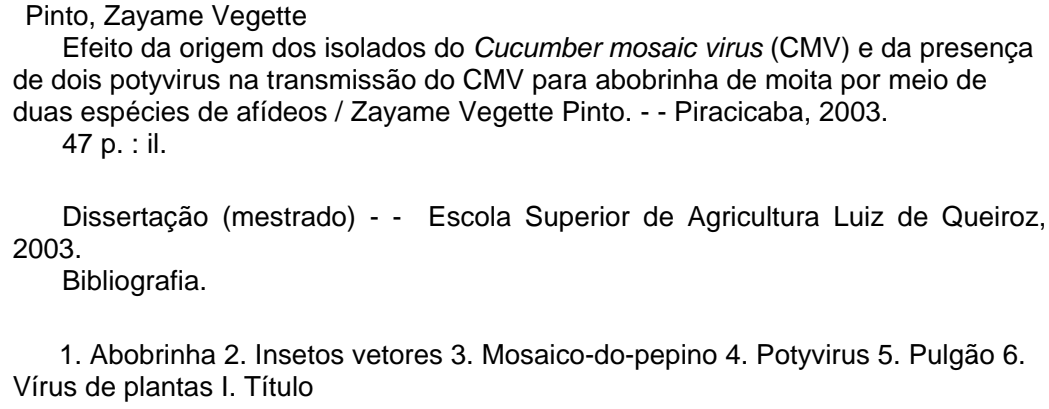

1. Abobrinha 2. Insetos vetores 3. Mosaico-do-pepino 4. Potyvirus 5. Pulgão 6. Vírus de plantas I. Título

CDD 635.62

\section{"Permitida a cópia total ou parcial deste documento, desde que citada a fonte - $\mathrm{O}$ autor"}


Ao meu avô Sebastião Vegette, aos meus pais José Luiz Pinto e Cleide Aparecida Vegette Pinto e

a minha irmã Tatiane Vegette Pinto pelo carinho, dedicação, cumplicidade e apoio incondicional ao longo de toda a minha vida, e, principalmente, durante $o$ processo do mestrado. 


\section{AGRADECIMENTOS}

À DEUS pela minha família, pela minha saúde, pelo meu esforço, pelo meu interesse, por minha dedicação nessa etapa importante da minha vida;

Á Escola Superior de Agricultura "Luiz de Queiroz" pela formação profissional; especialmente ao Departamento de Entomologia, Fitopatologia e Zoologia Agrícola por disponibilizar a estrutura e pela assistência necessária para a realização desse trabalho;

À Prefeitura do Campus "Luiz de Queiroz", de modo especial à CAVE, que possibilitou permanecer na Vila da Pós-Graduação;

Ao professor Dr. Jorge Alberto Marques Rezende por ter incentivado e orientado o meu ingresso na carreira científica e pelos valiosos ensinamentos acadêmicos, fundamentais para o meu desenvolvimento profissional;

À CAPES e ao CNPq por manterem um sistema de auxílio aos pesquisadores, indispensável para transpor as idéias do campo do pensamento para a vida real;

Aos professores do Setor de Fitopatologia pelos valorosos ensinamentos nas disciplinas; e também pelas cobranças que invariavelmente são responsáveis pelo amadurecimento pessoal, além de estimular o crescimento e desenvolvimento profissional;

Ao pesquisador do IAC/APTA Dr. Valdir A. Yuki pelo fornecimento, identificação e auxílio na manutenção da colônia de afídeos, pela amizade, 
pelos ensinamentos e conselhos, e por ter tornado mais leves os percalços durante o desenvolvimento deste trabalho;

Aos pesquisadores do Laboratório de Fitopatologia e de Bacteriologia do IB/APTA de Campinas, em especial ao Dr. Amaury e Dra. Flávia pelos conselhos e pela amizade que se estabeleceu durante o Estágio Vivencial e que me possibilitou colocar em prática os ensinamentos adquiridos durante minha vida acadêmica;

Aos funcionários, José Edivaldo, técnico do laboratório de Virologia Vegetal. A Silvia, técnica de laboratório, pela amizade e pela colaboração em experimentos realizados no decorrer das disciplinas do programa de Mestrado. Ao Rodolfo pelo auxílio durante o processo para a obtenção de antissoro. Ao Jeferson e a Marina por tornarem nossa vida acadêmica mais fácil. $E$ em especial ao Arthuso, funcionário da área experimental do Setor de Fitopatologia, e portanto um dos responsáveis diretos pelo êxito nos estudos desenvolvidos não só por mim, bem como pelos demais pesquisadores do departamento;

Aos colegas do Laboratório de Virologia Vegetal: Danilo, Davi, Débora, Estela, Juliana, José, Louise, Luiz Cláudio, Marília, Paulo, Quelmo, Ricardo e Scheila pela amizade e pelo convívio;

Aos colegas da Vila Estudantil pelo convívio; em especial Cláudia, Daniela e Vanderlei pela amizade e pelo apoio nos momentos difíceis;

À todos aqueles que direta ou indiretamente contribuíram para a realização deste trabalho. 


\section{SUMÁRIO}

Página

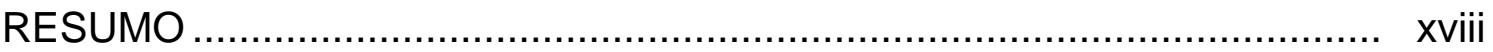

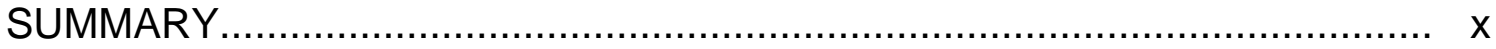

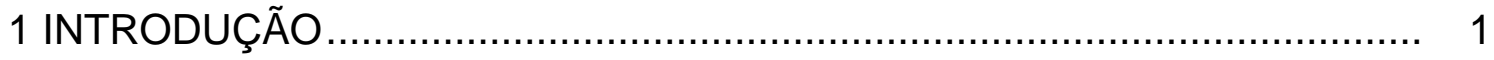

2 REVISÃO DE LITERATURA............................................................... 4

2.1 Incidência de viroses em cucurbitáceas ............................................... 4

2.2 Papaya ringspot virus-type W e Zucchini yellow mosaic virus ................... 7

2.3 Cucumber mosaic virus ................................................................... 10

2.4. Interferência entre vírus na transmissão por afídeos.................................11

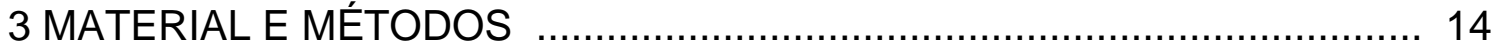

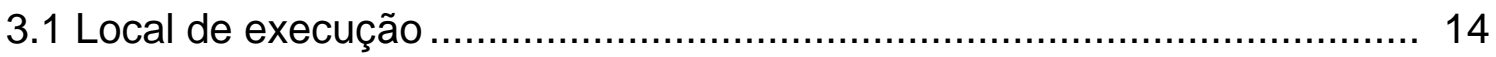

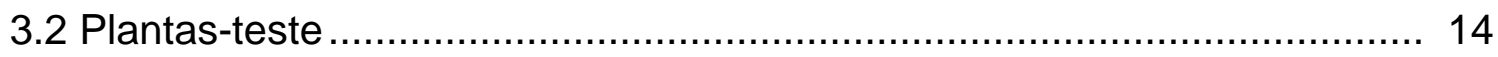

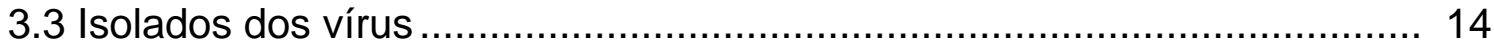

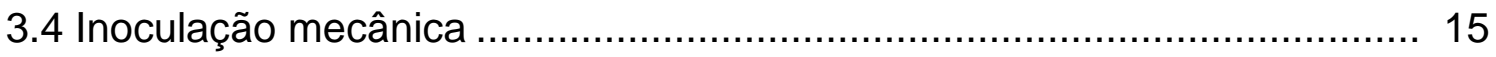

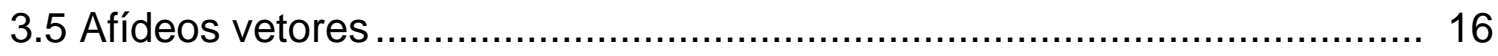

3.6 Transmissão com Aphis gossypii e Myzus persicae ............................... 16

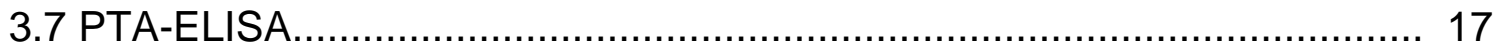

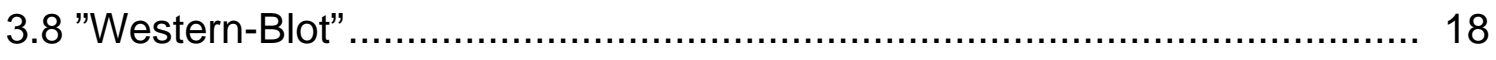

3.9 Teste da interferência de dois potyvirus na transmissão do CMV por

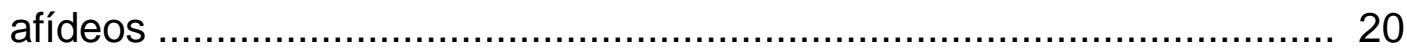

3.10 Teste do efeito da origem dos isolados do CMV na infectividade de abobrinha de moita ............................................................................... 21 
3.11 Estudo da mobilidade da proteína capsidial dos isolados do CMV em

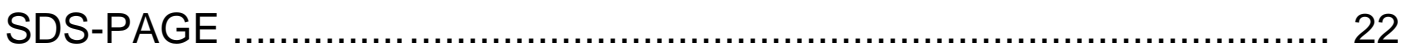

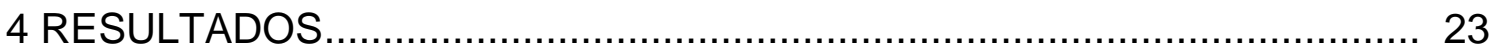

4.1 Interferência dos potyvirus na transmissão do CMV por afídeos ............... 23

4.2 Efeito da origem dos isolados do CMV na infectividade de abobrinha de

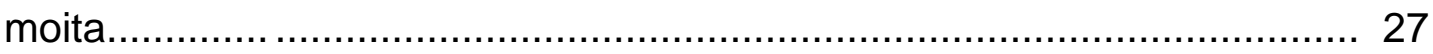

4.3 Mobilidade da proteína capsidial dos isolados do CMV em SDS-

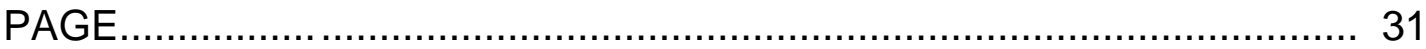

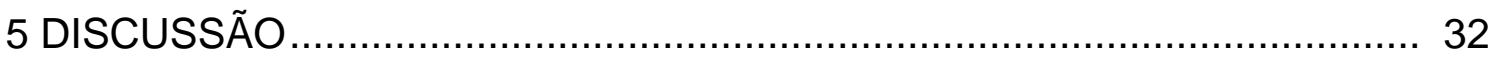

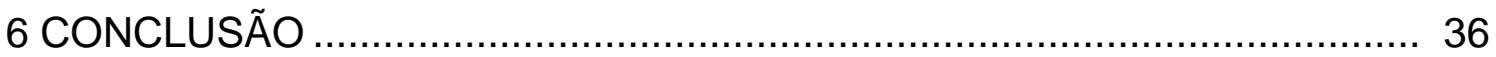

REFERÊNCIAS BIBLIOGRÁFICAS ...................................................... 37

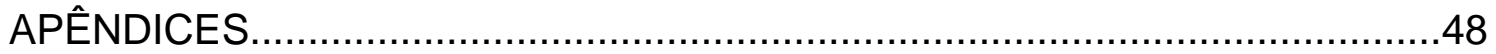




\title{
EFEITO DA ORIGEM DOS ISOLADOS DO Cucumber mosaic virus (CMV) E DA PRESENÇA DE DOIS POTYVIRUS NA TRANSMISSÃO DO CMV PARA ABOBRINHA DE MOITA POR MEIO DE DUAS ESPÉCIES DE AFÍDEOS.
}

\author{
Autor: ZAYAME VEGETTE PINTO \\ Orientador: Prof. Dr. JORGE ALBERTO MARQUES REZENDE
}

\section{RESUMO}

As cucurbitáceas no Brasil podem ser infectadas por diferentes vírus, tais como o Papaya ringspot virus - type W (PRSV-W); o Zucchini yellow mosaic virus (ZYMV) e o Cucumber mosaic virus (CMV). Os dois primeiros pertencem ao gênero Potyvirus e no geral ocorrem com maior freqüência do que o CMV, que é uma espécie do gênero Cucumovirus. Os dois potyvirus e o cucumovirus são transmitidos por afídeos de maneira não persistente. O principal objetivo desse trabalho foi o de obter subsídios que possam explicar a menor incidência do CMV em espécies de cucurbitáceas, estudando: (a) a interferência dos potyvirus PRSV-W e ZYMV na transmissão do CMV por Aphis gossypii e Myzus persicae para plantas de abobrinha de moita (Cucurbita pepo 'Caserta') e (b) o efeito de isolados do CMV provenientes de maracujazeiro (Passiflora edulis f. flavicarpa), de pimentão (Capsicum annuum), de pepineiro (Cucumis sativus), 
de meloeiro (Cucumis melo) e de trapoeraba (Commelina virginica) na infectividade de plantas de abobrinha de moita por meio da transmissão por afídeos. Para avaliar a possível interferência dos potyvirus na transmissão do CMV, as plantas de abobrinha de moita foram inoculadas com afídeos que adquiriram cada um dos vírus isoladamente; o CMV simultaneamente com cada um dos potyvirus; um dos potyvirus seguido pelo CMV e vice-versa. Os resultados mostraram, na maioria das vezes, que a transmissão dos vírus isoladamente foi mais eficiente do que em mistura, tanto através de aquisição simultânea como seqüencial. Os potyvirus no geral foram mais eficientemente transmitidos por ambas espécies de afídeos. Quando em mistura (aquisição simultânea ou sequencial), de uma maneira geral, houve uma redução na taxa de transmissão do CMV e do potyvirus presente na mistura. As avaliações sobre o efeito da origem dos isolados do CMV na infectividade de abobrinha de moita mostraram que apenas o isolado de pimentão não infectou plantas de abobrinha de moita quando transmitido por meio dos afídeos $A$. gossypii e $M$. persicae. Também não houve infecção quando inoculado mecanicamente. Os demais isolados infectaram abobrinha de moita através da transmissão por ambas espécies de afídeos. Análise da proteína capsidial dos diferentes isolados do CMV indicaram que todas apresentaram a mesma mobilidade em gel de SDS-PAGE. A origem do isolado o CMV, a eficiência da espécie de afídeo na sua transmissão e a interferência dos potyvirus PRSV-W e ZYMV podem explicar em parte a menor incidência desse cucumovirus em cucurbitáceas no país. 


\title{
EFFECT OF THE ORIGIN OF THE ISOLATES OF Cucumber mosaic virus (CMV) AND THE PRESENCE OF TWO POTYVIRUS IN THE TRANSMISSION OF CMV TO ZUCCHINI SQUASH BY TWO SPECIES OF APHIDS.
}

\author{
Author: ZAYAME VEGETTE PINTO \\ Adviser: Prof. Dr. JORGE ALBERTO MARQUES REZENDE
}

\section{SUMMARY}

The cucurbits in Brazil can be infected by different viruses, such as Papaya ringspot virus - type W (PRSV-W); Zucchini yellow mosaic virus (ZYMV) and Cucumber mosaic virus (CMV). The first two belong to the genus Potyvirus and in general they occur more frequently than CMV, which is a species of the genus Cucumovirus. The two potyviruses and the cucumovirus are transmitted by means of aphids in a non persistent way. The main objective of this work was to obtain subsidies that can explain the lower incidence of CMV in cucurbit species, studying: (a) the interference of the potyviruses PRSV-W and ZYMV in the transmission of CMV by means of Aphis gossypii and Myzus persicae to zucchini squash plants (Cucurbita pepo 'Caserta') and (b) the effect of isolates of CMV from passion flower (Passiflora edulis f. flavicarpa), bell pepper (Capsicum annuum), cucumber (Cucumis sativus), melon (Cucumis melo) and Commelina virginica in the infectividade of zucchini squash plants through the transmission by aphids. To evaluate the possible interference of the potyvirus in 
the transmission of CMV, zucchini squash plants were inoculated with aphids that acquired each one of the viruses separately; CMV simultaneously with each one of the potyvirus; one of the potyvirus follow by CMV and vice-versa. The results showed that the transmission of PRSV-W, ZYMV and CMV separately was more efficient than in mixture. The potyviruses in general were more efficiently transmitted by both species of aphids than CMV. When in mixture (simultaneous or sequential acquisition), there was a reduction in the rate of transmission of CMV as well as that of the potyvirus present in the mixture. The evaluation on the effect of the origin of the isolate of CMV in the infectivity of zucchini squash showed that only the isolate from bell pepper did not infected the plants when inoculated by means of $A$. gossypii and M. persicae. This isolate also did not infecte zucchini squash when inoculated mechanically. The others isolate infected zucchini squash when transmitted by both species of aphids. Analysis of the capsidial protein of the different isolates of CMV indicated that all presented the same mobility in SDS-PAGE. The origin of the isolate of CMV, the efficiency of the species of aphid and the interference of the potyviruses PRSV-W and ZYMV on its transmission can partly explain the lower incidence of this cucumovirus in cucurbits species in Brazil. 


\section{INTRODUÇÃO}

A família Cucurbitaceae é constituída de cerca de 118 gêneros e mais de 775 espécies. Dentre essas, várias são de grande valor econômico e social na horticultura alimentar mundial. No Brasil, as espécies com maior expressão econômica pertencem aos gêneros Cucurbita (abóbora, abobrinha e moranga), Cucumis (pepino, melão e maxixe), Citrullus (melancia), Sechium (chuchu) e Lagenaria (cabaça caxi). O cultivo das cucurbitáceas, tem um significativo valor econômico e alimentar, além de grande importância social, na geração de empregos diretos e indiretos, pois demanda um grande número de mão de obra desde o cultivo até a comercialização.

No Brasil a maior região produtora de cucurbitácea é a Nordeste, seguida pela região Sul e depois Sudeste. Como exemplos sobre o volume produzido nos últimos anos mencionam-se os casos da melancia (Citrullus lanatus), com a produção média em 2000 de 2.267.880 ton e de melão (Cucumis melo) com 174.710 ton. Os principais Estados produtores de melancia em 2000 foram a Bahia (427.720 ton), o Rio Grande do Sul (412.970 ton), São Paulo (244.850 ton) e Goiás (174.170 ton). Com relação à produção de melão, os principais Estados produtores foram Rio Grande do Norte (93.986 ton), Ceará (44.338 ton), Bahia (19.460 ton), Rio Grande do Sul (2.267 ton), Pernambuco (5.376 ton) e São Paulo (2.267 ton) (FNP Consultoria \& Comércio, 2003).

A produção de cucurbitáceas pode ser reduzida por diversos fatores, dentre eles as viroses. Mais de 20 vírus diferentes foram relatados infectando plantas dessa família na natureza (Lovisolo, 1980), sendo que oito deles já foram encontrados no Brasil até 1995: (a) o vírus do mosaico da abóbora - 
Squash mosaic virus - SqMV (Chagas, 1970); (b) o vírus do mosaico do pepino -Cucumber mosaic virus - CMV (Costa et al, 1972); (c) o vírus do mosaico do mamoeiro - estirpe melancia - Papaya ringspot virus - type W (Alburquerque et al, 1972) ; (d) o vírus da clorose letal da abobrinha - Zucchini lethal chlorosis virus - ZLCV (Kitajima \& Costa, 1972; Pozzer et al, 1994; Rezende et al, 1995); (e) o vírus da necrose da abóbora, provável Necrovirus (Lin et al, 1983); (f) o vírus do mosaico 2 da melancia - Watermelon mosaic virus -2 - WMV-2 (Sá \& Kitajima, 1991), (g) um possível Rhabdovirus (Kitajima et al, 1991) e (h) o vírus do mosaico amarelo da abobrinha - Zucchini yellow mosaic virus - ZYMV (Vega et al, 1992; 1995).

Entre os vírus encontrados infectando cucurbitáceas no Brasil, os três potyvirus (PRSV-W, ZYMV e WMV-2) e o cucumovirus (CMV) são transmitidos por diversas espécies de afídeos de maneira não persistente. Entre os potyvirus, o PRSV-W e o ZYMV, além de predominantes em várias regiões produtoras (Moura et al. 2001; Novaes et al. 1999, Oliveira et al. 2000, Stangarlin et al 2000 e 2001, Yuki et al. 2000), são vírus restritos às cucurbitáceas, embora haja relatos de infecção sistêmica de outras espécies como o ZYMV em outros países (Desbiez \& Lecoq, 1997). O CMV, apesar de ser transmitido da mesma maneira e possuir um círculo de hospedeiras envolvendo mais de 800 espécies vegetais (Palukaitis et al, 1992), geralmente tem apresentado menor incidência em cucurbitáceas no Brasil. Vários podem ser os fatores que contribuem para a menor incidência do CMV, como a resistência de campo das espécies de cucurbitáceas à infecção com esse vírus, variações nos isolados do vírus, interferência entre o CMV e outros vírus que infectam cucurbitáceas, e que têm vetores em comum, nos processos de aquisição e/ou transmissão, entre outros. Diante desses fatos e para melhor compreender a menor incidência do CMV em espécies de cucurbitáceas, o presente trabalho teve os seguintes objetivos: (a) estudar a possível interferência do PRSV-W e do ZYMV na transmissão do CMV pelos afídeos Aphis gossypii e Myzus persicae em plantas de abobrinha de moita; (b) 
estudar a infectividade de isolados do CMV, obtidos de diferentes espécies vegetais, quando inoculados em abobrinha de moita por meio dos afídeos $A$. gossypii e M. persicae. 


\section{REVISÃO DE LITERATURA}

\subsection{Incidência de viroses em cucurbitáceas}

A incidência de viroses em cucurbitáceas cultivadas é dinâmica, podendo variar em função da espécie de vírus e suas estirpes, do reservatório do vírus, da população e migração de vetores, das espécies e variedades vegetais cultivadas e das condições climáticas (Moura et al., 2001).

\section{No mundo}

Estudos sobre viroses de cucurbitáceas realizados na região do "Imperial Valley", na California, E.U.A., em 1959, mostraram que havia predominância de uma estirpe do vírus denominado na época por Watermelon mosaic virus (Grogan et al., 1959). O CMV era menos freqüente e o SqMV ocorria raramente. Na região central e no norte desse Estado o CMV e o SqMV eram mais comuns do que o Watermelon mosaic virus. Dez anos mais tarde, Milne et al. (1969) relataram que o WMV-2, o CMV e o SqMV eram os vírus mais freqüentes nas culturas de cucurbitáceas, com predominância do primeiro.

Umesh et al. (1995) estudaram a incidência de diferentes vírus em cucurbitáceas nas regiões dos Vales de San Joaquin e de Sacramento, na Califórnia, e constataram a predominância do WMV-2, do CMV e do Cucurbit aphid-borne yellow virus.

Outro estudo da ocorrência de viroses foi realizado por Grafton-Cardwell et al. (1996) em cultivo de meloeiro no Vale Central da Califórnia em que verificaram a predominância do WMV-2 (100\%), seguido do ZYMV (71\%), do CMV (63\%) e do PRSV-W (14\%). 
No Havaí, E.U.A., estudos sobre a incidência de viroses em cucurbitáceas nas ilhas de Oahu, Kauai e Hawaii, na década de 60, identificaram o PRSV-W, o WMV-2 e o CMV como os mais freqüentes (Shanmugasundaram et al., 1969). Nos anos de 1988 e 1989 foi realizado um novo estudo sobre viroses em cucurbitáceas nesse mesmo Estado norte americano que indicou mudanças significativas nos vírus presentes na região. O WMV-2 e o CMV não foram detectados em nenhuma das amostras coletadas nas ilhas de Maui, Molokai e Oahu. O ZYMV foi predominante nas ilhas Maui e Molokai, enquanto o PRSV-W predominou na ilha Ohau (Ullman et al., 1991).

Davis \& Mizuki (1987) estudando a ocorrência de viroses em meloeiro em Nova Jersey (E.U.A.), constataram que em 1983 houve maior incidência do WMV-2 (60\%), seguido do PRSV-W (6\%), do CMV (5\%) e do SqMV (1\%). O ZYMV não foi constatado. As infecções mistas com esses vírus variaram de $1 \mathrm{a}$ 9\%. Já em 1985 o ZYMV foi o vírus predominante com 23\% de incidência, seguido do WMV-2 (4\%). O PRSV-W e o CMV não foram constatados em infecções simples. Porém, foram encontrados em plantas com infecção mista, o PRSV-W e o WMV-2 (5\%); o PRSV-W e o ZYMV (11\%); o CMV, o WMV-2 e o ZYMV (2\%) e o PRSV-W, o WMV-2 e o ZYMV (20\%).

Luis-Arteaga et al. (1998) estudaram a ocorrência de viroses em meloeiro, nos anos de 1995 e 1996, na Espanha. Em 1995 os vírus encontrados foram o CMV (29\%), o WMV-2 (24\%), o PRSV-W (9\%) e o ZYMV (9\%). Em 1996, não foi encontrado o PRSV-W. O CMV e o WMV-2 continuaram os vírus predominantes com $22 \%$ e $21 \%$ de amostras infectadas, respectivamente, enquanto o ZYMV apareceu em 5\% das amostras analisadas.

No Libano, Abou-Jawdah et al. (2000) constataram que o ZYMV e o Cucurbit aphid-borne yellow virus (Polerovirus) foram os mais comuns em campos de cucurbitáceas. Em seguida apareceram o WMV-2, o PRSV-W e em menor porcentagem o CMV. 
Em levantamento de viroses em cucurbitáceas na Turquia, verificou-se a predominância do WMV-2 (22,4\%), seguida do ZYMV (14,5\%). O CMV foi constatado em 1,8\% das amostras. As infecções mistas do CMV com o ZYMV foram de 1,8\% e do CMV com o WMV-2 foram de 5,1\% (Sevik \& Arli - Sokmen, 2003).

\section{No Brasil}

No Estado do Ceará, Lima \& Vieira (1992) analisaram 118 amostras de cucurbitáceas (abóbora e abobrinha de moita) com sintomas de viroses e constataram que $80 \%$ estavam infectadas com o PRSV-W, $15 \%$ com o CMV e $5 \%$ com o SqMV. Dez anos mais tarde, nesse mesmo Estado, avaliações sobre incidência de viroses em campo experimental de meloeiro no município de Paraíba revelaram que o PRSV-W continuava predominante $(78,5 \%)$, seguido do WMV-2 (12\%), ZYMV (5,8\%), CMV (5,3\%). O SqMV não foi encontrado (Ramos et al., 2002).

Na região do Submédio do São Francisco, envolvendo os Estados da Bahia (BA) e de Pernambuco (PE), Lima et al. (1997) avaliaram a incidência de viroses na cultura da melancia. Foram analisadas 269 amostras, sendo que 49,1\% estavam infectada com o PRSV-W, 13\% com o WMV-2 e 1,9\% com o CMV. Posteriormente, novas avaliações em campos comerciais de meloeiro e de melancia revelaram que os vírus mais freqüentes foram o WMV-2 e o PRSV-W, com incidências de 68,7\% e 31,2\%, respectivamente (Cruz et al., 1999). Segundo esses autores a predominância do WMV-2 na região parece ser influenciada por fatores climáticos, alta virulência do patógeno, suscetibilidade das cultivares utilizadas e a população de vetores.

Oliveira et al. (2000), em pesquisa de viroses causadas por potyvirus em meloeiro e melancia nos Estados da Bahia (BA), do Ceará (CE), de Pernambuco (PE) e do Rio Grande do Norte (RN), verificaram a presença do 
PRSV-W, ZYMV e WMV-2, sendo que o primeiro foi o vírus mais comumente detectado nas áreas do CE e do RN. O ZYMV foi identificado em campos do CE e do RN e o WMV-2 apenas na BA e em PE.

Estudos sobre a incidência de vírus infectando cucurbitáceas no Estado de São Paulo indicaram que os mais freqüentemente encontrados foram o PRSV-W e o ZYMV, com incidências médias de 48,3\% e 24,5\%, respectivamente, de um total de 614 amostras analisadas. ZLCV, CMV e WMV2 foram detectados em 7,7\%, 5,9\% e 4,4\% das amostras, respectivamente (Yuki et al, 2000).

No Estado do Mato Grosso do Sul (MS), Stangarlin et al. (2000) constataram que das 103 amostras de cucurbitáceas analisadas, 57\% estavam infectadas com o PRSV-W, 34\% com o ZYMV e 5\% com o ZLCV. Entre as amostras infectadas 24 apresentaram infecção com mais de um vírus. Não foram encontradas plantas infectadas com o CMV e o WMV-2. Em outro estudo foram avaliados 31 genótipos de abóboras e abobrinha de moita, e mais uma vez o PRSV-W foi o vírus prevalecente (81\%). O ZLCV e o ZYMV foram constatados em $42 \%$ e $29 \%$ das amostras, respectivamente. O CMV e o SqMV tiveram incidências baixas, $6 \%$ e 3\%, respectivamente (Stangarlin et al., 2001).

Os resultados de identificação de espécies de vírus em áreas produtoras de abóbora, melancia, maxixe, pepino e melão no Estado do Maranhão revelaram o predomínio do PRSV-W e do WMV-2, com incidências de 64,4\% e 15,2\%, respectivamente. O CMV, o SqMV e o ZYMV foram encontrados em $6,8 \%, 3,4 \%$ e $3,4 \%$ das amostras analisadas, respectivamente (Moura et al., 2001).

\subsection{Papaya ringspot virus type-W e Zucchini yellow mosaic virus .}

O PRSV-W e o ZYMV são classificados taxonomicamente como espécies do gênero Potyvirus, da família Potyviridae. Suas partículas são alongadas, 
flexuosas, medindo aproximadamente $760-800 \mathrm{~nm}$ de comprimento por $12 \mathrm{~nm}$ de diâmetro. O genoma é constituído por uma molécula de RNA de fita simples senso positivo, que sintetizada uma poliproteína que após clivagens dá origem à diversas proteínas não estruturais com diferentes funções e à proteína capsidial (Lisa \& Lecoq, 1984, Purcifull et al, 1984; Desbiez \& Lecoq, 1997).

O PRSV-W causa sintomas de mosaico e deformidades foliares, redução no limbo foliar e no desenvolvimento vegetativo das plantas, redução na produção e na qualidade dos frutos, resultando em prejuízos que podem chegar a 100\% dependendo da espécie/cultivar de cucurbitácea infectada. O ZYMV, também causa doença do tipo mosaico em diversas espécies da família Cucurbitacea induzindo a malformação foliar, deformação e escurecimento dos frutos. Também podem causar danos da mesma magnitude do PRSV-W (Pavan, 1985; Yuki, 1990; Rezende, 1996; Lima et al., 1999; Giampan, 2002).

O PRSV-W infecta sistemicamente apenas espécies da família Cucurbitaceae (Gourgopal Roy et al., 1999 e Giampan \& Rezende, 2001). Há relatos de infecção experimental do PRSV-W em plantas da família Chenopodiaceae, porém os sintomas ficam localizados nas folhas inoculadas de Chenopodium amaranticolor e C. quinoa (Purcifull et al., 1984). As estirpes estudadas no Brasil até o momento não causaram lesão local nessas espécies (Oliveira et al., 2000).

O ZYMV ocorre naturalmente em diversas espécies da família Cucurbitaceae. Além das cucurbitáceas, o ZYMV infecta experimentalmente outras espécies vegetais pertencentes a 10 famílias de dicotiledôneas. A maioria dessas espécies exibem sintomas localizados nas folhas inoculadas ou infecção latente. A infecção experimental de algumas dessas espécies (Phaseolus vulgaris e Nicotiana benthamiana) depende da estirpe do ZYMV (Desbiez \& Lecoq, 1997). Na Jordânia, Moluccella laevis (Lameaceae) foi descrita como reservatório natural do ZYMV (Al-Musa, 1989). Plantas de 
Sesamum indicum exibiram sintomas severos de mosaico quando inoculadas com isolados do ZYMV, no Sudão (Mahgoub et al., 1997).

O PRSV-W e o ZYMV experimentalmente são facilmente transmitidos mecanicamente. O PRSV-W não é transmitido por sementes de cucurbitáceas, porém na literatura há relatos dessa modalidade de transmissão para o ZYMV (Al-Musa,1989; Greber et al., 1998; Schrijnwerkers et al., 1991).

O PRSV-W e o ZYMV são transmitidos por diferentes espécies de afídeos de maneira não persistente. Já foram descritas mais de 20 espécies vetoras do PRSV-W (Adlerz, 1974) e pelo menos 9 do ZYMV (Perring et al., 1992). Dentre os afídeos vetores desses vírus encontram-se as espécies $A$. gossypii, que é praga de algumas cucurbitácea (Gallo et al., 1998) e M. persicae, que em levantamento realizado por Costa (1970) foi uma das espécies mais frequentes.

A transmissão de espécies de potyvirus por afídeos é dependente da proteína capsidial (Matthews, 1991) e de uma proteína proteína não estrutural, denominada de componente auxiliar ("helper component protease"- HC-Pro), que é codificada pelo genoma viral e produzida somente nas células das plantas infectadas (Barnett, 1992). O conceito de componente auxiliar ('helper component") iniciou-se com os estudos realizados por Kassanis e Govier (1971). Os componentes auxiliares de diferentes potyvirus podem diferir nas suas propriedades biológicas (Pirone, 1981; Sako \& Ogata, 1981; Lecoq \& Pitrat, 1985) e serológicas (Thornbry \& Pirone, 1983). Biologicamente, o componente auxiliar de um potyvirus pode ou não auxiliar na transmissão de outro potyvirus por afídeos, mostrando certa especificidade nesse fenômeno.

Lecoq et al. (1991) estudaram a transmissão de dois isolados de ZYMV por M. persicae, um eficientemente transmitido por afídeo, denominado ZYMVHAT e outro com transmissão deficiente, denominado de ZYMV-PAT. Em testes de transmissão pelo afídeo utilizando o purificado viral do ZYMV-PAT com HCPro do ZYMV-HAT, conseguiram melhorar a eficiência de transmissão do 
ZYMV-PAT. Concluindo que o ZYMV-PAT possui alguma deficiência no HCPro, a qual prejudica sua transmissão por afídeos.

\subsection{Cucumber mosaic virus}

O CMV é classificado taxonomicamente como espécie da família Bromoviridae, gênero Cucumovirus. É um vírus cujas partículas são isométricas, com diâmetro de $29 \mathrm{~nm}$. O genoma viral é constituído por três moléculas de RNA de fita simples, senso positivo (Francki et al, 1979; Palukaitis et al., 1992). A proteína capsidial é sintetizada a partir de um RNA subgenômico (Francki et al, 1979).

As plantas de cucurbitáceas afetadas pelo CMV apresentam sintoma de mosaico. As folhas ficam com sintoma de epinastia, mosqueado, retorcidas, enrugadas e de tamanho reduzido. Os frutos têm seu tamanho reduzido e apresentam-se com deformações, mosqueado e verrugas (Kimati et al., 1997).

O CMV, diferentemente do PRSV-W e do ZYMV, possui uma ampla gama de hospedeiras, sendo capaz de infectar mais de 800 espécies vegetais (Palukaitis et al., 1992).

Há relatos de transmissão do CMV por sementes em 19 espécies vegetais, incluindo algumas plantas daninhas (Francki et al, 1979). O CMV também é transmitido experimentalmente por inoculação mecânica.

O CMV é transmitido de maneira não persistente por mais de 75 espécies de afídeos, como $A$. gossypii e $M$. persicae. A transmissão por afídeos depende somente da proteína capsidial. Estirpes do CMV podem apresentar diferentes taxas de transmissão por afídeos (Gera et al, 1979; Palukaitis et al., 1992).

Gera et al. (1979) realizaram experimento utilizando diferentes combinações entre a proteína capsidial e o RNA do isolado CMV-T com alta taxa de transmissão (90\%) e do isolado CMV-6 com baixa taxa de transmissão 
(10\%), verificaram que ocorreu aumento da transmissão do isolado CMV-6 quando substituiram sua proteína capsidial pela do CMV-T.

Brioso (1986) estudou características biológicas, serológicas e físicoquímicas de diversos isolados do CMV, provenientes de caupi, feijoeiro, fumo, gladíolo, maracujazeiro, melão de São Caetano, sálvia, trapoeraba e constatou que todos infectaram C. melo, C. sativus, C. moschata 'Menina Brasileira", C. pepo 'Caserta', Luffa aegyptica e L. cylindrica em teste de transmissão mecânica. No entanto, tentativa de transmissão desses isolados, exceto o de melão de São Caetano, por meio de afídeos M. persicae para C. pepo 'Caserta' falhou.

\subsection{Interferência entre vírus na transmissão por afídeos.}

Kassanis \& Govier (1971), em estudos de transmissão do Potato aucuba mosaic virus - PAMV (potexvirus) e do Potato virus Y - PVY (potyvirus) verificaram que a transmissão do PAMV depende do PVY, porém este não precisa estar presente na mistura para que o primeiro seja transmitido. Afídeos que se alimentaram primeiro em plantas infectadas com o PVY e depois foram transferidos para plantas infectadas com o PAMV, tornaram-se capazes de transmitir esse último. Isso ocorreu devido a utilização do HC-Pro do PVY na transmissão do PAMV.

Estudos realizados por Lecoq \& Pitrat (1985) mostraram a existência de alta especificidade do componente auxiliar na transmissão de três potyvirus (ZYMV, WMV-2 e PRSV-W) para plantas de melão. Essa especificidade foi encontrada comparando-se a transmissão desses vírus, misturados dois a dois em iguais concentrações, na presença do componente auxiliar de apenas um deles. A especificidade mais significativa ocorreu na mistura de purificados do ZYMV e do PRSV-W, com o componente auxiliar do último, quando os afídeos transmitiram o ZYMV com maior eficiência do que o PRSV-W. Segundo os 
autores, se esse fato ocorrer em plantas duplamente infectadas em campo, ele poderá propiciar certa vantagem epidemiológica para o ZYMV. Apesar das evidências concretas sobre o papel da proteína auxiliar na transmissão dos potyvirus por afídeos, o mecanismo de ação delas ainda não é bem conhecido. A idéia mais provável é a de que essa proteína possibilita a adesão do vírus a locais específicos nos estiletes dos afídeos, tornando possível a sua transmissão (Berger \& Pirone, 1986). Froissart et al. (2002) denominou de HCtranscomplementação quando o HC-Pro de um vírus auxilia na transmissão de outro.

Estudos também foram realizados com a estirpe $\mathrm{V}$ do Tomato aspermy virus -TAV (cucumovirus), que é transmitido por M. persicae, e a estirpe $M$ do CMV, que não é transmitida por essa espécie de afídeo. Quando os RNAs desses vírus foram encapsidados in vitro, separadamente, com a capa protéica da estirpe $V$ do TAV, ambos foram transmitidos pelo afídeo após aquisição através de membrana. Entretanto, a encapsidação com a proteína capsidial da estirpe $\mathrm{M}$ do $\mathrm{CMV}$ aboliu a transmissão do TAV por $M$. persicae (Chen \& Francki, 1990).

Banik e Zitter (1990) verificaram que a presença de infecção dupla do CMV e WMV-2 em cucurbitáceas tanto em campo experimental quanto em casa de vegetação tiveram mínimo efeito na eficiência de transmissão desses vírus por A. gossypii.

Outro exemplo de transmissão assistida entre potyvirus foi descrito por Bourdin \& Lecoq (1991) envolvendo um isolado do ZYMV, denominado ZYMVNAT, que não é transmitido por afídeos, devido a uma deficiência na proteína capsidial. Quando em infecção mista com um isolado do PRSV-W, este auxiliou na transmissão do ZYMV-NAT devido à ocorrência de hetero-encapsidação. Hobbs \& McLaughlin (1990) conseguiram também a transmissão de um isolado do Bean yellow mosaic virus - Scott (potyvirus), que não é transmitido isoladamente por Aphis craccivora para plantas de ervilha (Pisum sativum 
'Dwarf Gray Sugar'), quando auxiliada por outro potyvirus, o Pea mosaic virus -204-1. Neste caso, no entanto, concluiram que a não transmissão do BYMVScott pelo afídeo parece estar relacionada com propriedades do virion.

Roberts et al. (1993) estudaram a eficiência do afídeo $A$. craccivora na transmissão do CMV e do Cowpea aphid-borne mosaic virus para plantas de caupi cv. Tvu 76, após os afídeos terem adquirido esses vírus isoladamente e em mistura. No primeiro caso, $A$. craccivora foi mais eficiente na transmissão do CAMV (60\%) do que do CMV (20\%). No entanto, quando os afídeos adquiriram primeiro o potyvirus CAMV, seguido do CMV, somente o primeiro foi transmitido para $100 \%$ das plantas. 


\section{MATERIAL E MÉTODOS}

\subsection{Local de execução}

Os testes foram conduzidos em casa de vegetação do Departamento de Entomologia, Fitopatologia e Zoologia Agrícola da Escola Superior de Agricultura "Luiz de Queiroz", Universidade de São Paulo, Campus de Piracicaba (ESALQ/USP).

\subsection{Plantas - teste}

No trabalho foram utilizadas plantas de abobrinha de moita (Cucurbita pepo 'Caserta'), de pimentão (Capsium annuum) e de fumo (Nicotiana tabacum 'TNN'). As plantas foram obtidas através da semeadura em bandejas de isopor com substrato Plantmax Hortaliças HA da Eucatex Agro. Após a germinação, as mudas foram transferidas para vasos de alumínio de $16 \mathrm{~cm}$ de altura por 14,5 $\mathrm{cm}$ de diâmetro de boca contendo uma mistura autoclavada de terra e composto de matéria orgânica. Foram transplantadas de 2 a 3 mudas por vaso. As plantas foram mantidas em casa de vegetação, adubando-as regularmente com sulfato de amônio.

\subsection{Isolados dos vírus}

Neste estudo foram utilizados os seguintes isolados virais: (a) um isolado severo do PRSV-W obtido de abobrinha de moita em Campinas/SP; (b) um isolado severo do ZYMV também obtido de abobrinha de moita em Rinópolis/SP; (c) cinco isolados severos do CMV obtidos de maracujazeiro 
(Passiflora edulis f. flavicarpa), de pimentão (C. annuum), de pepineiro (Cucumis sativus), de meloeiro (C. melo) e de trapoeraba (Commelina virginica). O isolado do CMV de maracujazeiro foi obtido na região de Vera Cruz/SP, enquanto que o de trapoeraba foi cedido pelo Dr. Valdir A. Yuki, IAC/APTA. Os demais isolados do CMV foram gentilmente cedidos pelo $\mathrm{Dr}$. Rômulo F. Kobori da SAKATA Seed Sudamerica Ltda.

Os isolados do PRSV-W, do ZYMV e os do CMV provenientes de maracujazeiro, pepineiro, meloeiro e trapoeraba foram mantidos, separadamente, em plantas de abobrinha de moita em casa de vegetação. $O$ isolado do CMV proveniente de pimentão foi mantido em plantas de pimentão e de fumo em casa de vegetação.

Todos os isolados virais foram freqüentemente transferidos para novas plantas-teste, através de inoculação mecânica, para manutenção.

\subsection{Inoculação mecânica}

Os inóculos do PRSV-W, do ZYMV e do CMV foram obtidos a partir de folhas de plantas infectadas pelos respectivos vírus, macerando-as em almofariz de porcelana, em presença de tampão fosfato de potássio $0,02 \mathrm{M}, \mathrm{pH}$ 7,0 , contendo sulfito de sódio $0,02 \mathrm{M}$. As inoculações foram feitas em folhas previamente polvilhadas com carborundum friccionando-as com o indicador umedecido na solução de inóculo. As plantas de abobrinha de moita foram inoculadas no estádio cotiledonar, enquanto as de fumo e de pimentão foram inoculadas no estádio de 2 a 3 folhas. Em seguida as folhas foram lavadas com água para retirar o excesso de abrasivo e de inóculo existentes. As plantas inoculadas foram mantidas em casa de vegetação. 


\subsection{Afídeos vetores}

Como vetores foram usados os afídeos das espécies $A$. gossypii e $M$. percicae. A colônia de $A$. gossypii foi iniciada com pulgão proveniente de uma colônia mantida na ESALQ/USP em plantas de abobrinha de moita. A colônia de $M$. percicae foi iniciada com um único pulgão, proveniente de uma colônia mantida no Centro de Fitossanidade do Instituto Agronômico de Campinas (IAC/APTA - Campinas). Esse afídeo foi colocado em plantas de pimentão, para formação da colônia. Posteriormente esta foi mantida em plantas de pimentão e/ou nabiça (Raphanus raphanistrum). As plantas com as espécies de afídeos foram mantidas, separadamente, em gaiolas à prova de insetos, em condição de casa de vegetação.

\subsection{Transmissão com Aphis gossypii e Myzus persicae}

Os afídeos foram removidos das folhas de abobrinha de moita ( $A$. gossypii) e das folhas de nabiça e/ou pimentão (M. persicae), com um pincel fino e macio, passando-o levemente sobre eles. Estes, depois de coletados, foram mantidos em jejum, numa caixa plástica, por um período de aproximadamente $30 \mathrm{~min}$. A seguir foram colocados sobre plantas fontes dos diferentes vírus a serem estudados, de acordo com a finalidade dos testes descritos a seguir. O período de aquisição foi de aproximadamente 20 min. Para a transmissão, os afídeos foram transferidos para as folhas das plantasteste, em número de 5 afídeos por planta. Uma hora depois foi feita a pulverização com DECIS, para matar os afídeos ainda presentes. As plantas foram mantidas em casa de vegetação para posteriores avaliações de sintomas e indexação por PTA-ELISA. 


\subsection{PTA-ELISA}

A indexação das plantas-teste para a presença do CMV, do PRSV-W e do ZYMV foi feita através do teste serológico de ELISA ("Enzyme Linked Immunosorbent Assay"), do tipo PTA ("Plate Trapped Antigen"), conforme MOWAT \& DAWSON (1987), com algumas modificações.

Inicialmente as amostras das plantas a serem testadas foram maceradas individualmente em tampão carbonato de sódio pH 9,6 (0,015 $\mathrm{M} \mathrm{Na}_{2} \mathrm{CO}_{3}$, 0,035 $\mathrm{M} \mathrm{NaHCO}_{3}, 0,003 \mathrm{M} \mathrm{NaN}$, $1 \mathrm{~L} \mathrm{H}_{2} \mathrm{O}$ destilada), na diluição de aproximadamente 1:20. A seguir, $100 \mu \mathrm{L}$ dos extratos de cada amostra foram colocados em pocinhos da placa. Para cada amostra foram utilizados dois pocinhos. Nas placas também foram usados extratos de plantas sabidamente infectadas com cada um dos três vírus a serem testados, denominados controles positivos, e extratos de plantas sadias, controles negativos. As amostras foram incubadas na placa durante a noite à temperatura de aproximadamente $4^{\circ} \mathrm{C}$. Depois disso a placa foi lavada três vezes consecutivas com PBS-Tween pH 7,4 (0,0015 $\mathrm{M} \mathrm{KH}_{2} \mathrm{PO}_{4}, 0,14 \mathrm{M} \mathrm{NaCl}, 0,004 \mathrm{M} \mathrm{Na}_{2} \mathrm{HPO}_{4}$, $0,003 \mathrm{M} \mathrm{KCl}, 0,003 \mathrm{M} \mathrm{NaN}_{3}, 1 \mathrm{~L} \quad \mathrm{H}_{2} \mathrm{O}$ e 0,5 $\mathrm{mL}$ de Tween 20). Em seguida adicionaram-se $100 \mu \mathrm{L}$ de antissoros policlonais contra os vírus em análise, diluídos em tampão Tris- $\mathrm{HCl}$ pH 7,2 ( 0,2 M Tris- $\mathrm{HCl}, 0,15 \mathrm{M} \mathrm{NaCl}, 1 \mathrm{~L}$ de $\mathrm{H}_{2} 0$ ) na proporção de 1:1000 em cada pocinho da placa de ELISA. Esta foi incubada por $1,5 \mathrm{~h}$ a $37^{\circ} \mathrm{C}$. Os antissoros utilizados contra o PRSV-W, o ZYMV e o CMV foram produzidos no laboratório de Virologia Vegetal do Departamento de Entomologia, Fitopatologia e Zoologia Agrícola da Escola Superior de Agricultura "Luiz de Queiroz", Universidade de São Paulo, Campus de Piracicaba (ESALQ/USP). Novamente, a placa foi lavada três vezes consecutivas com PBS-Tween. Foram adicionados em cada pocinho da placa $100 \mu \mathrm{L}$ da Imunoglobulina $\mathrm{G}$ (IgG) conjugada com fosfatase alcalina (SIGMA9171), diluída 1:34000 em tampão Tris- $\mathrm{HCl}$. A placa foi incubada por 1,5 $\mathrm{h}$ a $37^{\circ}$ C. Depois foi novamente lavada por três vezes com PBS-Tween. 
Finalmente adicionaram-se em cada pocinho $100 \mu \mathrm{L}$ de $\rho$-fosfato de nitrofenil (SIGMA N-9389), diluído em tampão dietanolamina $\mathrm{pH}$ 9,8 $(97 \mathrm{~mL}$ dietanolamina, 0,003 $\mathrm{M} \mathrm{NaN}_{3}, 1 \mathrm{~L} \mathrm{H}_{2} \mathrm{O}$ ). A placa foi incubada durante 30 a 60 min, em condição ambiente, no escuro, para ocorrer a reação enzimática. As leituras de absorbância foram realizadas no leitor de ELISA Metertech $\Sigma 960$, utilizando-se filtro de $405 \mathrm{~nm}$. Uma amostra foi considerada positiva quando o valor médio da absorbância foi três vezes superior ao do extrato da planta sadia.

\section{8 "Western-Blot"}

A técnica de "Western-blot" foi utilizada para comparação de isolados do CMV, com base na mobilidade da proteína capsidial em gel de poliacrilamida submetido à eletroforese. O método foi aplicado de acordo com o protocolo descrito por Conci (1999). Inicialmente, foram extraídas as proteínas de tecidos foliares, macerando-os em tampão TE 1 X (TRIS 1,0 M, pH 7,4, EDTA 0,5 M, pH 8,0) na proporção de $0,25 \mathrm{~g}$ de folhas para $50 \mu \mathrm{L}$ de tampão. Duzentos $\mu \mathrm{L}$ desta suspensão foram misturados com igual volume de tampão de dissociação (TRIS 0,5 M, pH 6,8, SDS $5 \%, \beta$-mercaptoetanol $5 \%$, azul de bromofenol $0,05 \%$, glicerol $5 \%$ ). A desnaturação das proteínas foi completada incubandose as amostras em água fervente por 5 min.

As amostras foram submetidas à eletroforese em gel de poliacrilamida contendo dodecil sulfato de sódio (SDS-PAGE), utilizando-se um aparelho "Bio Rad Mini Protean II". O gel de separação foi composto por acrilamida 12,5\%, TRIS $1,5 \mathrm{M}, \mathrm{pH} 8,8$, SDS $0,1 \%$, APS $0,1 \%$ e TEMED $0,033 \%$ e o gel de empilhamento por acrilamida $4 \%$, TRIS $1,0 \mathrm{M}$, pH 6,8, SDS 1\%, APS $1 \%$ e TEMED 0,05\%. Cada canaleta do gel recebeu $10 \mu \mathrm{L}$ das amostras a serem analisadas. Uma canaleta recebereu $10 \mu \mathrm{L}$ de proteínas marcadoras, com pesos moleculares na faixa de $10 \mathrm{kDa}$ a $250 \mathrm{kDa}$ (Rainbow, Amersham LIFE SCIENCE). Promoveu-se a eletroforese por $20 \mathrm{~min}$ a $95 \mathrm{~V}$, até a linha frontal do 
azul de bromofenol atingir o gel separador. Em seguida a voltagem foi elevada para $125 \mathrm{~V}$. A corrida foi interrompida quando as amostras chegaram na base do gel.

Posteriormente, as proteínas separadas no gel de poliacrilamida foram transferidas para uma membrana de nitrocelulose, empregando-se tampão de transferência (TRIS 1,0 M, glicine 1,5\%, metanol 20 \%). A transferência foi feita em um aparelho "Bio Rad Mini trans-blot cell" por 90 min a 0,25 mA.

A membrana contendo as proteínas das amostras foi submetida a uma reação serológica, a fim de revelar a presença da proteína capsidial do vírus analisado. Inicialmente, a membrana foi lavada por 2 a 3 min com TBS (TRIS $0,002 \mathrm{M}, \mathrm{pH} 7,4, \mathrm{NaCl} 0,15 \mathrm{M}$ ). Em seguida, foi incubada em TBS/Tween contendo $7,5 \%$ de leite em pó desnatado, por $30 \mathrm{~min}$, à temperatura ambiente. Posteriormente foi transferida para uma suspensão de anticorpo específico contra o vírus a ser testado, diluído 1:1000, em TBS/Tween contendo leite em pó desnatado $7,5 \%$, incubando-a sob agitação constante, durante 3 a 4 h, à temperatura ambiente. Decorrido esse tempo a membrana foi lavada, 3 vezes consecutivas, com TBS/Tween, durante 3 minutos cada vez. A seguir, foi incubada por 2 a $3 \mathrm{~h}$ sob agitação constante, à temperatura ambiente, em uma solução contendo imunoglobulina G (IgG) conjugada com fosfatase alcalina (SIGMA A-8025), diluída 1:32.000 em TBS/Tween + leite em pó desnatado $7,5 \%$. Depois desse período lavou-se a membrana conforme descrito acima. Então, adicionou-se o substrato 5-bromo-4-cloro-3-indolyl fosfato (BCIP)/nitro blue tetrazolium (NBT), assim preparado: $25 \mu \mathrm{L}$ BICP(Promega); $50 \mu \mathrm{L}$ NBT (Promega) diluídos em $10 \mathrm{~mL}$ de tampão substrato pH 9,5 (TRIS 1M, $80 \mathrm{~mL}$ de água deionizada, acrescidos de 5,84 $\mathrm{g}$ de $\mathrm{NaCl}$ e 1,02 $\mathrm{g}$ de $\mathrm{MgCl}$ ). A reação foi interrompida lavando-se a membrana com água destilada. 


\subsection{Teste da interferênica de dois potyvirus na transmissão do CMV por afídeos}

Para avaliar a interferência dos potyvirus (PRSV-W e ZYMV) na transmissão do isolado de CMV proveniente de pepineiro para plantas de abobrinha de moita foram realizados seis experimentos em épocas diferentes, sendo três com $M$. persicae e três com A. gossypii. Em cada experimento foram comparados os seguintes tratamentos:

(1) plantas inoculadas com afídeos que adquiriram somente o CMV;

(2) plantas inoculadas com afídeos que adquiriram somente o PRSV-W;

(3) plantas inoculadas com afídeos que adquiriram o PRSV-W simultaneamente com o CMV

(4) plantas inoculadas com afídeos que adquiriram o CMV seguido pelo PRSV-W;

(5) plantas inoculadas com afídeos que adquiriram o PRSV-W seguido pelo CMV;

Outros seis experimentos foram realizados para comparar os mesmos tratamentos, substituindo-se o PRSV-W pelo ZYMV.

Em cada tratamento foram inoculadas seis a nove plantas. As plantas foram mantidas em casa de vegetação para avaliações com base nos sintomas, duas semanas após a inoculação. Em seguida, amostras foliares dessas plantas foram submetidas ao teste de PTA-ELISA. 


\subsection{Teste do efeito da origem dos isolados do CMV na infectividade de abobrinha de moita}

Para estudar a infectividade dos isolados do CMV foram realizados dois experimentos usando como vetor o afídeo $A$. gossypii, comparado-se os seguintes tratamentos:

(1) plantas de abobrinha de moita inoculadas com afídeos que adquiriram o CMV isolado de pepineiro e mantido em plantas de abobrinha de moita;

(2) plantas de abobrinha de moita inoculadas com afídeos que adquiriram o CMV isolado de maracujazeiro e mantidos em plantas de abobrinha de moita;

(3) plantas de abobrinha de moita inoculadas com afídeos que adquiriram o CMV isolado de meloeiro e mantido em plantas de abobrinha de moita;

(4) plantas de abobrinha de moita inoculadas com afídeos que adquiriram o CMV isolado de trapoeraba e mantido em plantas de abobrinha de moita;

(5) plantas de abobrinha de moita inoculadas com afídeos que adquiriram o CMV isolado de pimentão e mantido em plantas da mesma espécie;

(6) plantas de abobrinha de moita inoculadas com afídeos que adquiriram o CMV isolado de pimentão e mantido em plantas de fumo;

No caso do isolado de CMV proveniente de pimentão foram incluidos mais três tratamentos:

(7) plantas de pimentão inoculadas com afídeos que adquiriram o CMV isolado de pimentão e mantido em plantas dessa espécie; 
(8) plantas de fumo inoculadas com afídeos que adquiriram o CMV isolado de pimentão e mantido dessa espécie;

(9) plantas de fumo inoculadas com afídeos que adquiriram o CMV isolado de pimentão e mantido em plantas de fumo.

Outros dois experimentos foram realizados para comparar os mesmos tratamentos, excluindo-se os tratamentos (8) e (9), substituindo-se o afídeo vetor A. gossypii por M. persicae.

Depois de inoculadas as plantas foram mantidas em casa de vegetação para avaliações com base nos sintomas. A confirmação da infecção foi feita por PTA-ELISA.

Também foram realizados testes complementares de transmissão mecânica do isolado de CMV proveniente de plantas de pimentão, mantido em plantas de pimentão e fumo, para C. annuum cv. Magali, C. pepo cv. Caserta, C. moschata cv. Menina brasileira, Cucumis sativus cv. Caipira, C. lanatus cv. Crimson Sweet, Nicotiana clevelandii, Nicotiana tabacum cvs.TNN, Turkishi e Havana. Cada tratamento foi constituído por seis repetições. As plantas após inoculação foram mantidas em casa de vegetação para avaliação dos sintomas. Depois foram analisadas por PTA-ELISA.

\subsection{Estudo da mobilidade da proteína capsidial dos isolados do CMV em SDS-PAGE}

Cada isolado do CMV foi inoculado mecanicamente em plantas de abobrinha de moita. O isolado de CMV proveniente de pimentão foi inoculado em plantas de pimentão. As plantas foram mantidas em casa de vegetação. Depois de três semanas foram coletadas amostras foliares das plantas infectadas com cada isolado separadamente. As folhas foram maceradas em tampão TE 1X para a extração de proteínas totais, as quais submetidas a uma análise de "Western blot", conforme descrita em 3.8. 


\section{RESULTADOS}

\subsection{Interferência dos potyvirus na transmissão do CMV por afídeos.}

O conjunto dos resultados de três experimentos independentes sobre 0 efeito do PRSV-W na transmissão do isolado de CMV de pepineiro pelos afídeos $A$. gossypii e $M$. persicae estão apresentados na Tabela 1. Os resultados individuais dos experimentos estão no Apêndice 1.

Verifica-se que esse potyvirus, isoladamente, foi eficientemente transmitido por ambas espécies de afídeos. A eficiência de transmissão do $\mathrm{CMV}$, quando adquirido isoladamente pelas duas espécies de afídeos, foi em média 50\% inferior àquela do PRSV-W isoladamente. No entanto, quando os afídeos adquiriram esse potyvirus em mistura com o cucumovirus, ou primeiro o PRSV-W seguido pelo CMV, ou vice-versa, a eficiência de transmissão de ambos foi reduzida. Mesmo assim, a transmissão do PRSV-W predominou sobre a do CMV. Já as infecções mistas variaram de 4\% a 21\%, porém foram ligeiramente mais altas nos casos em que os vírus foram adquiridos de fontes distintas, de forma sequencial. 
Tabela 1. Interferência do Papaya ringspot virus - type W (PRSV-W) na eficiência de transmissão do Cucumber mosaic virus (CMV) por Aphis gossypii e Myzus persicae em abobrinha de moita. Total de três experimentos distintos.

\begin{tabular}{|c|c|c|c|}
\hline \multirow[t]{2}{*}{ Tratamentos * } & \multicolumn{3}{|c|}{ Plantas inoculadas/ plantas infectadas $(\%)^{\star \star}$} \\
\hline & CMV & PRSV-W & 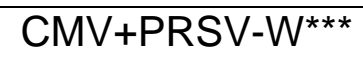 \\
\hline & \multicolumn{3}{|c|}{ Aphis gossypii } \\
\hline CMV & $24 / 13(54)$ & $24 / 0(0)$ & $24 / 0(0)$ \\
\hline PRSV-W & $24 / 0(0)$ & $24 / 22(92)$ & $24 / 0(0)$ \\
\hline CMV+PRSV-W & 24/8(33) & $24 / 14(58)$ & $24 / 2(8)$ \\
\hline $\mathrm{CMV} \rightarrow \mathrm{PRSV}-\mathrm{W}$ & 24/7 (29) & $24 / 12(50)$ & $24 / 5(21)$ \\
\hline \multirow[t]{2}{*}{ PRSV-W $\rightarrow$ CMV } & $24 / 9(38)$ & $24 / 9(38)$ & $24 / 3(13)$ \\
\hline & \multicolumn{3}{|c|}{ Myzus persicae } \\
\hline CMV & 24/9 (38) & $24 / 0(0)$ & $24 / 0(0)$ \\
\hline PRSV-W & $24 / 0(0)$ & $24 / 22(92)$ & $24 / 0(0)$ \\
\hline CMV+PRSV-W & $24 / 4(17)$ & 24/17 (71) & $24 / 1(4)$ \\
\hline $\mathrm{CMV} \rightarrow \mathrm{PRSV}-\mathrm{W}$ & $24 / 5(21)$ & 24/17 (71) & 24/4 (17) \\
\hline $\mathrm{PRSV}-\mathrm{W} \rightarrow \mathrm{CMV}$ & $24 / 4(17)$ & 24/15 (63) & 24/4 (17) \\
\hline \multicolumn{4}{|c|}{$\begin{array}{l}\text { * CMV: plantas inoculadas com afídeos que adquiriram somente o CMV; PRSV-W: plantas } \\
\text { inoculadas com afídeos que adquiriram somente o PRSV-W; CMV+PRSV-W: plantas } \\
\text { inoculadas com afídeos que adquiriram simultaneamente o CMV e o PRSV-W; CMV } \rightarrow \text { PRSV-W } \\
\text { plantas inoculadas com afídeos que adquiriram o CMV seguido do PRSV-W; PRSV-W } \rightarrow \text { CMV } \\
\text { plantas inoculadas com afídeos que adquiriram o PRSV-W seguido do CMV. }\end{array}$} \\
\hline \multicolumn{4}{|c|}{ ** Números de plantas inoculadas/número de plantas infectadas (\% de plantas infectadas). } \\
\hline
\end{tabular}


Também foram realizados três experimentos independentes de interferência do ZYMV na transmissão do CMV pelas mesmas espécies de afídeos em abobrinha de moita. Os resultados estão agrupados na Tabela 2, enquanto aqueles dos experimento individualizados estão no Apêndice 2.

Neste caso, quando usou-se A. gossypii a eficiência de transmissão do ZYMV e do CMV adquiridos isoladamente foi semelhante. Porém, quando usouse $M$. persicae a eficiência de transmissão do potyvirus foi $59 \%$ maior que a do CMV. Quando os afídeos A. gossypii ou M. persicae adquiriram o CMV e o ZYMV simultaneamente ou sequencialmente ocorreu uma diminuição na eficiência de transmissão do ZYMV, quando comparado com a transmissão deste isoladamente. A eficiência de transmissão do CMV pelo A. gossypii, quando na presença do ZYMV, foi variável em função da sequência de aquisição desses vírus. O mesmo ocorreu quando usou-se a espécie $M$. persicae. As infecções mistas variaram de $4 \%$ a $17 \%$. 
Tabela 2. Interferência do Zucchini yellow mosaic virus (ZYMV) na eficiência de transmissão do Cucumber mosaic virus (CMV) por Aphis gossypii e Myzus persicae em abobrinha de moita. Total de três experimentos distintos.

\begin{tabular}{|c|c|c|c|}
\hline \multirow[t]{2}{*}{ Tratamentos * } & \multicolumn{3}{|c|}{ Plantas inoculadas/ plantas infectadas (\%) } \\
\hline & CMV & ZYMV & $\mathrm{CMV}+\mathrm{ZYMV} \mathrm{V}^{\star \star \star}$ \\
\hline & \multicolumn{3}{|c|}{ Aphis gossypii } \\
\hline CMV & $24 / 12(50)$ & $24 / 0(0)$ & $24 / 0(0)$ \\
\hline ZYMV & $24 / 0(0)$ & $24 / 13(54)$ & $24 / 0(0)$ \\
\hline CMV+ZYMV & $24 / 12(50)$ & 24/4(17) & $24 / 1(4)$ \\
\hline $\mathrm{CMV} \rightarrow \mathrm{ZYMV}$ & 24/6(25) & 24/7 (29) & $24 / 4(17)$ \\
\hline \multirow[t]{2}{*}{$\mathrm{ZYMV} \rightarrow \mathrm{CMV}$} & $24 / 15(63)$ & 24/3 (13) & 24/3 (13) \\
\hline & \multicolumn{3}{|c|}{ Myzus persicae } \\
\hline CMV & $24 / 2(8)$ & $24 / 0(0)$ & $24 / 0(0)$ \\
\hline ZYMV & $24 / 0(0)$ & 24/16 (67) & $24 / 0(0)$ \\
\hline CMV+ZYMV & 24/7 (29) & $24 / 10(42)$ & $24 / 2(8)$ \\
\hline $\mathrm{CMV} \rightarrow \mathrm{ZYMV}$ & $24 / 4(17)$ & 24/11 (46) & $24 / 2(8)$ \\
\hline ZYMV $\rightarrow$ CMV & $24 / 2(8)$ & $24 / 6(25)$ & $24 / 1(4)$ \\
\hline \multicolumn{4}{|c|}{$\begin{array}{l}{ }^{*} \mathrm{CMV} \text { : plantas inoculadas com afídeos que adquiriram somente o CMV; ZYMV: plantas } \\
\text { inoculadas com afídeos que adquiriram somente o ZYMV; CMV+ZYMV: plantas inoculadas com } \\
\text { afídeos que adquiriram simultaneamente o CMV e o ZYMV; CMV } \rightarrow Z Y M V \text { : plantas inoculadas } \\
\text { com afídeos que adquiriram o CMV seguido do ZYMV; ZYMV } \rightarrow \mathrm{CMV} \text { : plantas inoculadas com } \\
\text { afídeos que adquiriram o ZYMV seguido do CMV. }\end{array}$} \\
\hline \multicolumn{4}{|c|}{ ** Números de plantas inoculadas/número de plantas infectadas (\% de plantas infectadas). } \\
\hline
\end{tabular}




\subsection{Efeito da origem dos isolados do CMV na infectividade de abobrinha de moita}

O resultado conjunto dos dois testes de transmissão dos diferentes isolados do CMV para plantas-teste de abobrinha de moita, pimentão e fumo por A. gossypii e M. persicae estão nas tabelas 3 e 4, respectivamente.

Tabela 3. Transmissão de isolados do Cucumber mosaic virus (CMV), provenientes de diferentes espécies vegetais, para diferentes plantas-teste por meio do afídeo Aphis gossypii.

\begin{tabular}{cccc}
\hline $\begin{array}{c}\text { Origem dos isolados } \\
\text { de CMV }\end{array}$ & $\begin{array}{c}\text { Planta fonte de } \\
\text { inóculo }\end{array}$ & $\begin{array}{c}\text { Planta -teste } \\
\text { inoculada }\end{array}$ & $\begin{array}{c}\text { Pl. inoc./ Pl. infect. } \\
(\%)^{*}\end{array}$ \\
\hline $\begin{array}{c}\text { P. edulis f. flavicarpa } \\
\text { C. melo }\end{array}$ & C. pepo & C. pepo & $35 / 14(40)$ \\
C. sativus & C. pepo & C. pepo & $35 / 23(66)$ \\
C. annuum & C. annuum & C. pepo & $35 / 22(63)$ \\
C. annuum & N. tabacum & C. annuum & $06 / 05(83)$ \\
C. annuum & C. annuum & N. tabacum & $06 / 01(17)$ \\
C. annuum & C. annuum & C. annuum & $10 / 03(30)$ \\
C. annuum & N. tabacum & N. tabacum & $10 / 08(80)$ \\
C. virginica & C. pepo & C. pepo & $35 / 22(63)$
\end{tabular}

* Números de plantas inoculadas/número de plantas infectadas (\% de plantas infectadas). 
$\mathrm{Na}$ tabela 3, observam-se que os isolados de CMV provenientes de cucurbitáceas (pepineiro e meloeiro) e trapoeraba foram mais eficientemente transmitidos por $A$. gossypii para abobrinha de moita do que o isolado proveniente de maracujazeiro. $\mathrm{O}$ isolado de CMV proveniente de plantas de pimentão, mantidos em plantas dessa espécie não foram transmitidos por $A$. gossypii para plantas de abobrinha de moita. Esse mesmo isolado, quando mantido em plantas de fumo foi transmitido de forma bastante eficiente para plantas de pimentão e de fumo. Quando a fonte de inóculo desse isolado de CMV foi o pimentão, a eficiência de transmissão por $A$. gossypii para plantas da mesma espécie e de fumo foi substancialmente reduzida.

Quando os testes de transmissão foram realizados com a espécie $M$. persicae (Tabela 4), os resultados foram semelhantes aos obtidos com $A$. gossypii, porém a porcentagem de transmissão foi no geral bem inferior. Os isolados de CMV provenientes de maracujazeiro, meloeiro, pepineiro e trapoeraba foram transmitidos para abobrinha de moita. Mais uma vez, o isolado do CMV proveniente de pimentão, adquirido pelo afídeo de plantas de pimentão ou de fumo, não foi transmitido para abobrinha de moita. Esse mesmo isolado não foi transmitido por esse afídeo de plantas de pimentão para pimentão. 
Tabela 4. Transmissão de isolados do Cucumber mosaic virus (CMV), provenientes de diferentes espécies vegetais, para diferentes plantas-teste por meio do afídeo Myzus persicae.

\begin{tabular}{cccc}
\hline $\begin{array}{c}\text { Origem dos isolados } \\
\text { de CMV }\end{array}$ & $\begin{array}{c}\text { Plantas fonte de } \\
\text { inoculo }\end{array}$ & $\begin{array}{c}\text { Planta } \\
\text { inoculada }\end{array}$ & $\begin{array}{c}\text { PI. inoc./ PI. infect. } \\
(\%) *\end{array}$ \\
\hline $\begin{array}{c}\text { C. edulis f. flavicarpa } \\
\text { C. melo }\end{array}$ & C. pepo & C. pepo & $29 / 01(3)$ \\
C. sativus & C. pepo & C. pepo & $29 / 02(7)$ \\
C. annuum & C. annuum & C. pepo & $29 / 04(14)$ \\
C. annuum & C. annuum & C. annuum & $20 / 0(0)$ \\
C. annuum & N. tabacum & C. pepo & $06 / 0(0)$ \\
C. virginica & C. pepo & C. pepo & $29 / 01(3)$
\end{tabular}

* Números de plantas inoculadas/número de plantas infectadas (\% de plantas infectadas).

Devido a não transmissão do isolado de CMV proveniente de plantas de pimentão, mantido na mesma espécie, para plantas de abobrinha de moita pelas duas espécies de afídeos, foi realizado um experimento complementar para avaliar a eficiência da transmissão mecânica desse isolado para diferentes espécies vegetais. Os resultados desse experimento estão apresentados na Tabela 5 . 
Tabela 5. Transmissão mecânica do isolado do Cucumber mosaic virus (CMV) proveniente de plantas de Capsicum annuum e mantidos na mesma espécie, para diferentes espécies vegetais.

\begin{tabular}{ll}
\hline \multicolumn{1}{c}{ Plantas inoculadas } & PI. inoculadas./PI. infectadas* \\
\hline Cucurbita pepo 'Caserta' & $6 / 0$ \\
C. moschata 'Menina Brasileira' & $6 / 0$ \\
Cucumis sativus 'Caipira' & $6 / 0$ \\
Citrullus lanatus 'Crimson Sweet' & $6 / 0$ \\
Nicotiana clevelandii & $5 / 5$ \\
N. tabacum 'Havana' & $6 / 6$ \\
N. tabacum 'TNN' & $4 / 4$ \\
N. tabacum 'Turkishi' & $6 / 6$ \\
Capsicum annuum 'Magali' & $5 / 5$ \\
* Número de plantas inoculadas/ número de plantas com sintoma após 15 dias.
\end{tabular}

$O$ isolado de CMV proveniente de pimentão não foi transmitido mecanicamente para nenhuma das quatro espécies de cucurbitáceas inoculadas. Porém, foi transmitido para plantas de pimentão, 3 cultivares de $N$. tabacum e para N. clevelandi com $100 \%$ de eficiência. A infecção dessas plantas foi confirmada por PTA-ELISA (Tabela 3). 


\subsection{Mobilidade da proteína capsidial dos isolados do CMV em SDS-PAGE}

O resultado obtido está apresentado na Figura 1. Nota-se que a proteína capsidial de todos os isolados de CMV estudados apresentaram a mesma mobilidade em SDS-PAGE, sugerindo que todos possuem proteína capsidial com o mesmo peso molecular (aproximadamente $24 \mathrm{KDa}$ ).

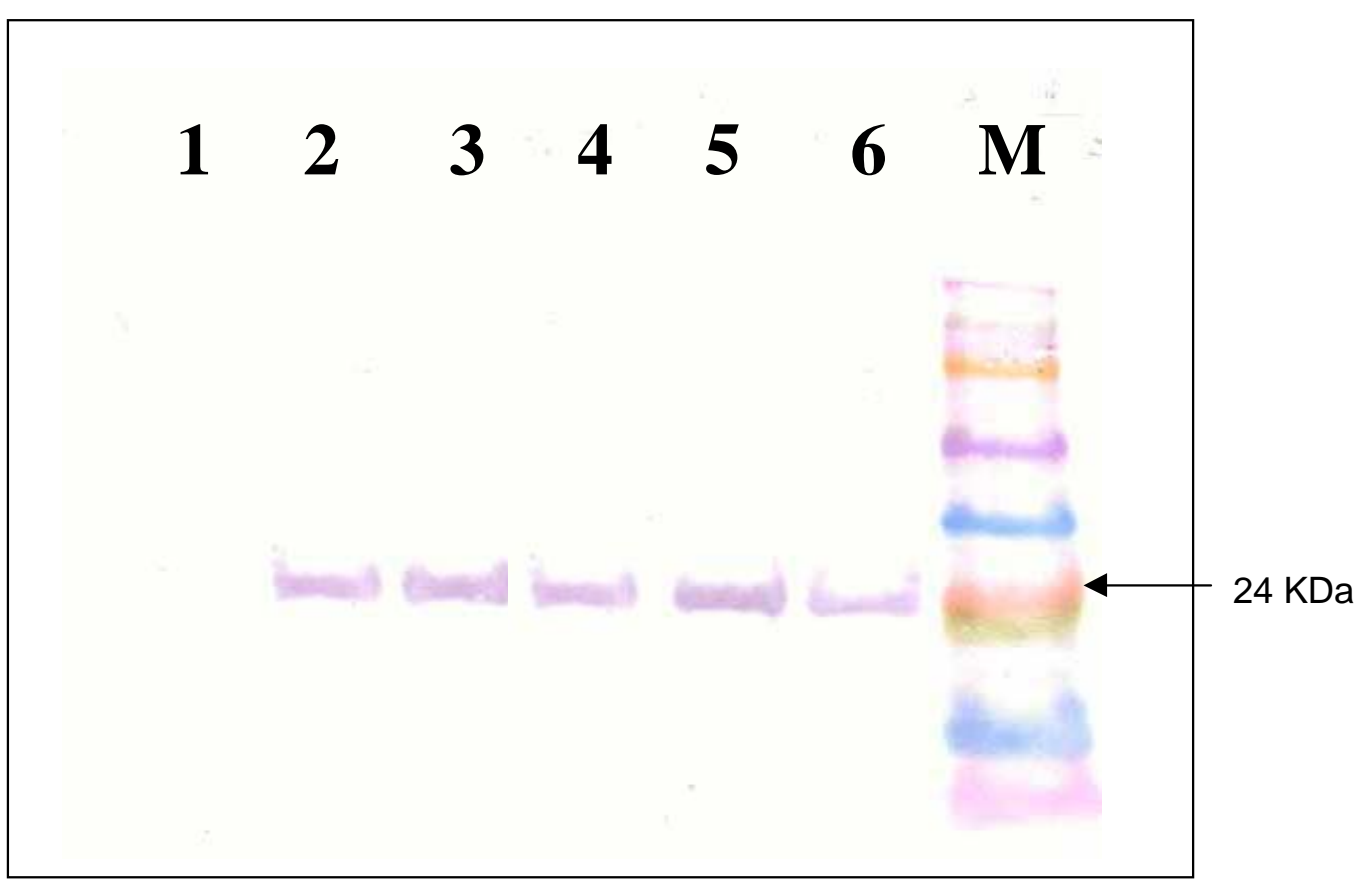

Figura 1 - Reação de "Western blot" com antissoro contra a proteína capsidial do Cucumber mosaic virus. M: marcador de peso molecular de proteína Rainbow -Amersham Life Science, 1: extrato de planta sadia de abobrinha, 2: CMV proveniente de maracujazeiro, 3: CMV proveniente de meloeiro 4: $\mathrm{CMV}$ proveniente de pepineiro, 5: CMV proveniente de plantas de trapoeraba, 6: CMV proveniente de plantas de pimentão. 


\section{DISCUSSÃO}

No Brasil o PRSV-W é até o momento o vírus predominante na maioria das regiões produtoras de cucurbitáceas, como mostram os levantamentos de viroses feitos por Oliveira et al. (2000), Stangarlin et al. (2000 e 2001), Yuki et al. (2000), Moura et al. (2001), entre outros.

O ZYMV foi relatado pela primeira vez no sul do Estado de São Paulo e em Santa Catarina (Vega et al., 1992; Caner et al., 1992), sendo posteriormente constatado em seis outros Estados do Brasil (Oliveira et al., 2000; Poltronieri et al., 2000; Stangarlin et al., 2000; Moura et al., 2001). Depois do PRSV-W, é o vírus que tem sido encontrado com maior incidência em cucurbitáceas em São Paulo (Yuki et al., 2000).

O CMV foi relatado pela primeira vez no Brasil em São Paulo causando doença em bananeira (Silbershimidt \& Nóbrega, 1941). Em cucurbitáceas, um dos primeiros relatos de infecção com esse vírus foi feito por Costa et al. (1972) em campo de pepino, mas com baixa incidência. Estudos mais recentes sobre a incidência de viroses em cucurbitáceas feitos no Brasil não detectaram o CMV (Cruz et al., 1999; Novaes et al., 1999, Stangarlin et al., 2000) ou detectaram com baixa incidência (Oliveira et al., 2000; Yuki et al., 2000; Moura et al., 2001; Stangarlin et al., 2001).

Em alguns outros países o CMV também aparece com baixa ou nenhuma incidência em cucurbitáceas (Grogan et al., 1959; Davi \& Mizuki, 1987; Servi \& Arli-Sokmen, 2003). Mas, há relatos em países como Espanha e E.U.A. em que o CMV é a espécie predominante em cucurbitáceas (Umesh et al., 1995; Grafton-Cardwell et al., 1996; Luis-Artega et al., 1998). 
O presente trabalho procurou estudar duas variáveis que podem estar relacionadas com a menor incidência do CMV em cucurbitáceas no Brasil: interação com dois potyvirus, predominantes em diferentes regiões do país, no processo de transmissão do CMV por duas espécies de afídeos ( $A$. gossypii e M. persicae) e o efeito da origem do isolado do CMV na infectividade de abobrinha de moita.

Analisando-se inicialmente a transmissão isolada do PRSV-W, do ZYMV e do CMV, constatou-se que os dois primeiros foram mais eficientemente transmitidos pelos afídeos A. gossypii e M. persicae do que o CMV, sendo este último afídeo ligeiramente mais eficiente do que o primeiro na transmissão do ZYMV. No caso da transmissão do PRSV-W, os resultados diferem daqueles obtidos por Ardlerz (1974), Yuki (1990) e Giampan \& Rezende (2001) que constataram ser a espécie M. persicae mais eficiente do que $A$. gossypii. Para a transmissão do ZYMV os resultados foram semelhantes ao relatado por Castle et al. (1992), onde as eficiências de transmissão de $A$. gossypii e $M$. persicae foram de $35 \%$ e $41 \%$, respectivamente. Quando compararam duas espécies de Aphis na transmissão do ZYMV, Yuan \& Ullman (1996) verificaram que $A$. craccivora foi mais eficiente (52\%) do que A. gossypii $(11,7 \%)$.

Para que um vírus seja transmitido por um afídeo é necessário que os processos de aquisição e de transmissão sejam efetuados de maneira eficiente. Assim, sendo, pode-se sugerir, com base nos resultados do presente trabalho, que o CMV deva ser menos eficientemente adquirido do que os dois potyvirus por essas espécies de afídeos, com conseqüente menor taxa de transmissão, o que poderia em parte explicar a sua menor incidência em cucurbitáceas. É importante lembrar que a concentração do vírus no tecido vegetal também pode influenciar a eficiência de transmissão, embora essa característica não tenha sido investigada nesse trabalho.

Quanto a interferência desses dois potyvirus na transmissão do CMV pelos afídeos $A$. gossypii e $M$. persicae, os resultados mostraram que nos 
testes de aquisição simultânea (CMV + potyvirus) ou seqüencial (CMV $\rightarrow$ potyvirus ou potyvirus $\rightarrow \mathrm{CMV}$ ) sempre ocorreu uma redução na taxa de transmissão das duas espécies de potyvirus e do CMV quando transmitido em associação com o PRSV-W. Quando a transmissão do CMV foi feita em associação com o ZYMV a taxa de transmissão do cucumovirus foi variável. Mesmo assim, na maioria dos testes houve uma predominância na transmissão dos dois potyvirus. Fato semelhante foi em parte constatado por Robert et al. (1993) em testes de transmissão do CAMV e do CMV por A. craccivora. Quando o afídeo adquiriu o CMV seguido do CAMV, somente o potyvirus foi transmitido para plantas de caupi cv.Tvu76. Assim sendo, pode-se sugerir que a aquisição do CMV juntamente com o PRSV-W e o ZYMV (simultaneamente ou seqüencialmente) também pode contribuir para a menor incidência do cucumovirus em cucurbitáceas. Embora os dados obtidos não permitam explicações para essa interferência parcial, pode-se supor que a maior taxa de transmissão dos potyvirus esteja associada com a maior eficiência da proteína HC-Pro no processo de aquisição/transmissão dos potyvirus por essas duas espécies de afídeos, do que a capa protéica do CMV, responsável pela transmissão desse vírus por afídeos.

A origem dos isolados do CMV, isto é a espécie vegetal da qual ele foi obtido, também parece ser um outro fator que pode contribuir para a menor incidência desse vírus em cucurbitáceas. Os resultados evidenciaram que o isolado proveniente de pimentão não foi capaz de infectar abobrinha de moita, tanto através da inoculação com afídeos como por meio mecânico. Também não infectou outras espécies de cucurbitáceas quando transmitido mecanicamente. Os demais isolados de CMV foram transmitidos pelas duas espécies de afídeos, sendo que a eficiência de $A$. gossypii variou de $40 \%$ a $60 \%$ e a de $M$. persicae variou de $3 \%$ a $14 \%$. Costa et al. (1987) também constataram diferenças em transmissão de isolados de CMV provenientes de feijoeiro, de melão de São Caetano, de sálvia, de gladíolo e de comelina, para 
plantas de Nicotiana rustica, Physalis sp. e pimentão cv. Agronômico $10 \mathrm{G}$. Embora esses isolados tenham sido transmitidos pelo afídeo $M$. persicae, ficou evidente que o isolado de melão de São Caetano foi transmitido com eficiência muito inferior à dos demais isolados estudados. Brioso (1986) não obteve sucesso na transmissão de 7 isolados do CMV, provenientes de diferentes espécies vegetais, para plantas de C. pepo 'Caserta', por meio do afídeo $M$. persicae. No entanto, todos os isolados foram facilmente transmitidos mecanicamente para 6 espécies de cucurbitáceas.

Como o isolado de CMV de pimentão não foi capaz de infectar abobrinha de moita por meio da transmissão por afídeos nem por inoculação mecânica, é possível que outro gene viral, diferente daquele que codifica a proteína capsidial, que está associada com a transmissão por afídeos esteja relacionado com essa característica. A proteína capsidial dos diferentes isolados do CMV não diferiram quanto ao peso molecular, analisado por meio da mobilidade em SDS-PAGE.

Nesse estudo constatou-se ainda que a taxa de infecção mista entre os potyvirus e o CMV foi relativamente baixa, variando de 4\% a 21\%. Embora não tenha sido objetivo desse trabalho analisar esse tipo de infecção, os resultados obtidos foram semelhantes aos de infecção mista que ocorrem em condições naturais em campo (Stangarlin et al., 2000; Yuki et al., 2000; Stangarlin et al., 2001). 


\section{CONCLUSÃO}

A origem do isolado o CMV, a eficiência da espécie de afídeo na sua transmissão e a interferência dos potyvirus PRSV-W e ZYMV podem explicar em parte a menor incidência desse cucumovirus em cucurbitáceas no país. 


\section{REFERÊNCIAS BIBLIOGRÁFICAS}

ABOU-JAWDAH, Y.; SOBH, H.; EL-ZAMMAN, S.; FAYYAD, A.; LECOQ, H. Incidence and management of virus diseases of cucurbits in Lebanon. Crop Protection, v. 19, p. 217-224, 2000.

ADLERZ, W.C. Spring aphid fhights and incidence of watermelon mosaic virus 1 and 2 in Florida. Phytopathology, v. 64, p. 350-353, 1974.

ALBUQUERQUE, F.C.; IKEDA, H.; COSTA A.S. Ocorrência do vírus do mosaico da melancia (Citrullus vulgaris Schrad.) em plantações de melão (Cucumis melo L.) na região de Belém-PA. Revista de Olericultura, v. 12, p. 94,1972 /resumo/.

AL-MUSA, A.M. Oversummering hosts for some cucurbit viruses in the Jordan Valley. Journal of Phytopathology, v. 127, p. 49-54, 1989.

BANIK, N.T.; ZITTER, T.A. Determination of Cucumber mosaic virus titer in muskmelon by enzyme-linked immunosorbent assay and correlation with aphid transmission. Plant Disease, v. 74, p. 857-859, 1990.

BARNETT, O.W. Potyvirus taxonomy. Archives of Virology, Supplementum 5. Springer Verlag, New York. p. 450, 1992. 
BERGER, P.H.; PIRONE, T.P. The effect of helper component on the uptake and localization of potyviruses in Myzus persicae. Virology, v. 153, p. 256261, 1986.

BOURDIN, D.; LECOQ, H. Evidence that heteroencapsidation between two potyviruses is involved in aphid transmission of a non-aphid-transmissible isolate from mixed infections. Phytopathology, v. 81, p. 1459-1464, 1991.

BRIOSO, P.S.T. Caracterização biológica, físico-química e sorológica de isolados do vírus do mosaico do pepino (Cucumber mosaic vírus) no Brasil. Brasília, 1986. p. 121. Dissertação (Mestrado), Universidade de Brasília, 1986.

CASTLE, S.J.; PERRING, T.M.; FARRAR, C.A.; KISHABA, A.N. Field and laboratory transmission of Watermelon mosaic virus 2 and Zucchini yellow mosaic virus by various aphid species. Phytopathology, v. 82, p. 235-240, 1992.

CANER, J.; GALLETI, S.R.; LOTZ, I.P.M.; OLIVEIRA, J.M. Natural infection of cucumber (Cucumis sativus) by Zucchini yellow mosaic virus (ZYMV) in Santa Catarina, Brazil. In. Encontro Nacional de Virologia, 11., Sociedade Brasileira de Virologia, p. 180, 1992 /resumo/.

CHAGAS, C. M. Mosaico da abóbora em pepino. O Biológico, v. 36, p. 326, 1970.

CHEN, B.; FRANCKI, R.I.B. Cucumovirus transmission by the aphid Myzus persicae is determined solely by the viral coat protein. Journal of General. Virology, v. 71, p. 939-944, 1990. 
CONCI, V.L. Técnicas serológicas. In: DOCAMPO, D. M.; LENARDÓN, S.L. (Ed). Métodos para detectar patógenos sistêmicos. Córdoba: IFFIVEINTAJICA, p. 23-39, 1999.

COSTA, C.L. Variações sazonais da migração de Myzus persicae em Campinas nos anos de 1967 a 1969. Bragantia, v. 29, p. 347-359, 1970.

COSTA, A.S.; KITAJIMA, E.W.; NAGAI, H. Alguns vírus que afetam o pepino (Cucumis sativus L.) em São Paulo. Revista de Olericultura, v. 12, p. 100101, 1972 /resumo/.

COSTA, C.L.; DE SÁ, P.B.; RIBEIRO, S.G. Transmissão do vírus do mosaico do pepino pelo afídeo Myzus persicae. Fitopatologia Brasileira, v. 12, p. 148, 1987 /resumo/.

CRUZ, E.S.; PAZ, C.D.; PIO-RIBEIRO, G.; BATISTA, D.C.; PEREIRA FILHO, G.G.; ANDRADE, G.P. Levantamento de viroses em melancia e melão no submédio São Francisco. Summa Phytopatologica, v. 25, p. 21, 1999 /resumo/.

DAVIS, R.F.; MIZUKI, M.K. Detection of cucurbit viruses in New Jersey. Plant Disease, v. 71, p. 40-44, 1987

DESBIEZ, C.; LECOQ, H. Zucchini yellow mosaic virus. Plant Pathology, v. 46, p. 809-829, 1997.

DOUINE, L.; QUIOT, J.B.; MARCHOUX, G.; ARCHANGE, P. Recensement des espèces végetales sensibles au virus de la mosaique du concombre (CMV): étude bibliografique. Annales de Phytopathologie, v. 11, p. 439-475, 1979. 
FNP CONSULTORIA \& COMÉRCIO. Agrianual 2003 Anuário da Agricultura Brasileira. São Paulo, 2003, p. n. 406-445.

FRANCKI, R.I.B.; MOSSOP, D.W.; HATTA, T. Cucumber mosaic virus. CMI/AAB. Descriptions of Plant Viruses, n.213, p. 4, 1979.

FROISSART, R.; MICHALAKIS, Y.; BLANC, S. Helper componenttranscomplementation in the vector transmission of plant viruses. Phytopthology, v. 92, p. 576-579, 2002.

GALLO, D.; NAKANO, O.; SILVEIRA NETO,S.; CARVALHO, R.P.L.; BATISTA, G.C. DE; BERTI FILHO, E.; PARRA, J.R.P.; ZUCCHI, R.A.; ALVES, S.B.; VENDRAMIM, J.D. Manual de Entomologia Agrícola. 2.ed. São Paulo: Editora Agronômica Ceres, 1988. 649p.

GeRA, A.; LOEBENSTEIN, G.; RACCAH, B. Protein coats of two strains of cucumber mosaic virus affect transmission by Aphis gossypii. Phytopthology, v. 69, p. 396-399, 1979.

GIAMPAN, J.S. Infectividade e proteção de três estirpes fracas do Papaya ringspot virus em plantas de melancia. Piracicaba, 2002. 63p. Dissertação (Mestrado) - Escola Superior de Agricultura "Luiz de Queiroz", Universidade de São Paulo.

GIAMPAN, J.S.; REZENDE, J.A.M. Transmissibilidade por afídeos e reação de diversas espécies vegetais às estirpes fracas premunizantes do PRSV-W. Summa Phytopathologica, v. 27, p. 279-283, 2001.

GOURGOPAL ROY; JAIN, R.K.; BHAT, A.I.; VARMA, A. Comparative host range and serological studies of papaya ringspot potyvirus isolates. Indian Phytopathology, v. 52, p. 14-17, 1999. 
GRAFTON-CARDWELL, E.E.; PERRING, T.M.; SMITH, R.F.; VALENCIA, J.; FARRAR, C.A. Occurrence of mosaic viruses in melons in the Central Valley of California. Plant Disease, v. 80, p. 1092-1097, 1996.

GREBER, R.S.; PERLEY, D.M.; HERRINGTON, M.E. Some characteristics of Australian isolates of Zucchini yellow mosaic virus. Australian Journal of Agricultural Research, v. 39, p. 1085-1094, 1998.

GROGAN, R.G.; HALL, D.H.; KIMBLE, K.A. Cucurbit mosaic viruses in California. Phytopathology, v. 49, p. 366-376, 1959.

HOBBS, H.A.; MCLAUGHLIN, M.R. A non-aphid-transmissible isolate of Bean yellow virus-scott that is transmissible from mixed infections with Pea mosaic virus-204-1. Phytopathology, v. 80, p. 268-272, 1990.

KIMATI, H.; AMORIM, L.; BERGAMIN FILHO, A.; CAMARGO, L.E.A.; REZENDE, J.A.M. Manual de Fitopatologia, 3. ed. São Paulo: Editora Agronômica Ceres, 1997. v.2, 776p: Doenças das plantas cultivadas.

KASSANIS, B.; GOVIER, D.A. New evidences on the mechanism of transmission of potato $C$ and potato aucuba mosaic viruses. Journal of General Virology, v.10, p. 99-101, 1971.

KITAJIMA, E.W.; COSTA, A.S. Alterações no complexo de Golgi associada a infecção de tecido foliar de plantas infectadas por uma estirpe do vírus do vira-cabeça. Revista da Sociedade Brasileira de Fitopatologia, v.5, p. 180-181, 1972 /resumo/.

KITAJIMA, E.W.; SÁ, P.B.; DE, RITZINGER, C.H.S.P.; RODRIGUES, M.G.R. Detecção de partículas do tipo rhabdovirus em algumas compostas, aboboreira e mamoeiro. Fitopatologia Brasileira, v. 16, p. 141-144, 1991. 
OLIVEIRA, V.B.; LIMA, J.A.A.; VALE, C.C.; PAIVA, W.O. Caracterização biológica e sorológica de isolados de potyvirus obtidos de cucurbitáceas no nordeste brasileiro. Fitopatologia Brasileira, v. 25, p. 628-636, 2000.

LECOQ, H.; PITRAT, M. Specificity of the Helper-componet - mediated aphid transmission of three potyviruses infecting muskmelon, Phytopathology, $p$. 890-893, 1985.

LECOQ, H.; LEMAIRE, J.M.; WIPF-SCHEIBEL. Control of Zucchini yellow mosaic virus in squash by cross protection. Plant Disease, v. 75, p. 208211, 1991.

LIMA, M.F.; BARBOSA, L.F.; ÁVILA, A.C. de. Levantamento de viroses na cultura da melancia na região do Submédio São Francisco. Fitopatologia Brasileira, v. 22, p. 337, 1997 /resumo/.

LIMA, M.F.; QUEIROZ, M.A. de; DIAS, R. de C.S. Avaliação de germoplasma de melancia a viroses no Submédio do vale São Francisco. Horticultura Brasileira, v. 17, p. 20-22, 1999 /resumo/.

LIMA, J.A.A.; VIEIRA, A.C. Distribuição do vírus do mosaico da abóbora em municípios cearences e gama de hospedeiros de um isolado. Fitopatologia Brasileira, v. 17, p. 112-114, 1992.

LIN, M.T.; KITAJIMA, E.W.; MUNHOZ, J.O. Isolamento e propriedade do vírus da necrose da abóbora, um possível membro do grupo "Tobacco Necrosis Virus". Fitopatologia Brasileira, v. 8, p. 622, 1983 /resumo/.

LISA, V.; LECOQ, H. Zucchini yellow mosaic virus. CMI/AAB. Descriptions of Plant Viruses n. 282, p. 4, 1984. 
LOVISOLO, O. Virus and viroid diseases of cucurbits. Acta Horticultura, v. 88, p. 33-71, 1980.

LUIS-ARTEGA, M.; ALVAREZ, J.M.; ALONSO-PRADO, J.L.; BERNAL, J.J.; GARCÍA-ARENAL, F.; LAVIÑA, A.; BATLLE, A.; MORIONES, E. Occurrence, distribution, and relative incidence of mosaic viruses infecting field-grown melon in Spain. Plant Disease, v. 82, p. 979-982, 1998.

MAHGOUB, H.A.; DESBIEZ, C.; WIPF-SCHEIBEL, C.; DAFALLA, G.; LECOQ, $\mathrm{H}$. Characterization and occurence of Zucchini yellow mosaic virus in sudan. Plant Pathology, v. 46, p. 800-805, 1997.

MATTHEWS, R.E.F. Plant virology, 3 ed. San Diego: Academic Press. 1991. p.380.

MILNE, K.S.; GROGAN, R.G.; KIMBLE, K.A. Identification of viruses infecting cucurbits in California. Phytopathology, v. 59, p. 819-828, 1969.

MOURA, M.C.C.L.; LIMA, J.A.A.; OLIVEIRA, V.B.; GONÇALVES, M.F.B. Identificação sorológica de espécies de vírus que infectam cucurbitáceas em áreas produtoras do Maranhão. Fitopatologia Brasileira, v. 26, p. 9092, 2001.

MOWAT, W.P.; DAWSON, S. Detection of plant viruses by ELISA using crude sap extracts and unfractionated antisera. Journal of Virological Methods, v.15, p.233-247, 1987.

NG, J.; PERRY, K.L. Stability of the aphid transmission phenotype in Cucumber mosaic virus. Plant Pathology, v. 48, p. 388-394, 1999. 
NOVAES, Q.S.; REZENDE, J.A.M.; KITAJIMA, E.W. Ocorrência dos vírus do mosaico amarelo e da clorose letal em cucurbitáceas no Estado da Bahia. Summa Phytopathologica, v. 25, p. 37, 1999.

OLIVEIRA, V.B.; LIMA, J.A.A., VALE, C.C.; PAIVA, W.O. Caracterização biológica e sorológica de isolados de potyvirus obtidos de cucurbitáceas no nordeste brasileiro. Fitopatologia Brasileira, v. 25, p. 628-636, 2000.

PALUKAITIS, S.P.; ROOSSINK, M.J.; DIETZGEN, R.G.; FRANCKI, R.I.B. Cucumber mosaic virus. Advances in Virus Research, v. 41, p. 281-348, 1992.

PAVAN, M.A. Vírus do mosaico da melancia: purificação, viabilidade e distribuição nas principais regiões produtoras de pepino e abobrinha de Minas Gerais. Viçosa, 1985. 69 p. Dissertação (Mestrado) - Universidade Federal de Viçosa.

PERRING, T.M.; FARRAR, C.A.; MAYBERRY, K.; BLUA, M.J. Research reveals patern of cucurbit virus spread. California Agriculture, v. 36, p. 35-40, 1992.

PERRY, K.L.; ZHANG, L.; PALUKAITIS, P. Amino acid changes in coat protein of Cucumber mosaic virus differentially affect transmission by the aphids Myzus persicae and Aphis gossypii. Virology, v. 242, p. 2105-2114, 1998.

PIRONE, T.P. Efficiency and selectivity of the helper component mediated aphid transmission of purified potyviruses. Phytopathology, v.71, p.922-924, 1981.

POLTRORIERI, L.S.; NOVAES, Q.S.; DIAS, P.R.P.; REZENDE, J.A.M.; TRINDADE, D.R.; ALBUQUERQUE, F.C.; KITAJIMA, E. W. Constatação do 
Zucchini yellow mosaic virus em cucurbitácaes no Estado do Pará. Fitopatologia Brasileira, v. 25, p. 669, 2000.

POZZER, L.; NAGATA, T.; LIMA, M.I.; KITAJIMA, E.W.; RESENDE, R. DE O.; DE ÁVILA, A.C. A new tospovirus infecting Cucurbitaceae in Brazil. Fitopatologia Brasileira, v.19, p.21, 1994 /resumo/.

PURCIFULL, D.; EDWARDSON, J.; HIEBERT, E.; GONSALVES, D. Papaya ringspot virus. CMI/AAB. Description of Plant Viruses, n. 292, 1984. 8p.

RAMOS, N.F.; LIMA, J.A.A.; SANTOS, A.A.; GONÇALVES, M.F.B. Plantas de meloeiro com infecção mista de espécies de vírus em campos experimentais. Fitopatologia Brasileira, v. 27, p. 211, 2002 /resumo/.

REZENDE, J.A.M.; GALLETI, S.R.; SCAGLIUSI, S.M.M.; POZZER, L.; RESENDE, R. DE. O.; DE ÁVILA, A.C. Incidência e algumas características biológicas e serológicas de um tospovirus em abobrinha-de-moita em São Paulo. Fitopatologia Brasileira, v. 20, p. 343, 1995 /resumo/.

REZENDE, J.A.M. Premunização de duas espécies e um híbrido de Cucurbita para o controle do mosaico causado pelo vírus do mosaico do mamoeiro estirpe melancia. Piracicaba, 1996. 88p. Tese (Livre-Docência) - Escola Superior de Agricultura "Luiz de Queiroz", Universidade de São Paulo.

ROBERTS, J.M.F.; THOTTAPPILLY, G.; HODGSON, G.J. The ability of Aphis craccivora, A. gossypii and $A$. citricola to transmit single and mixed viruses to cowpeas. Journal Phytopathology, v. 138, p. 164-170, 1993.

SÁ, P.B. DE; KITAJIMA, E.W. Characterization of an isolate of watermelon mosaic virus 2 (WMV-2) from Brazil. Fitopatologia brasileira, v. 16, p. $217-$ 233, 1991. 
SAKO, N.; OGATA, K. Different helper factors associated with aphid transmission of some potyviruses. Virology, v. 112, p. 762-765, 1981.

SCHRIJNWERKERS, C.C.F.M.; HUIJBERTS, N.; BOS, L. Zucchini yellow mosaic virus; two outbreaks in the Netherlands and seed transmissibility. Netherlands Journal of Plant Pathology, v. 97, p. 187-191, 1991.

SEVIK, M.A.; ARLI-SOKMEN, M. Viruses infecting cucurbits in Samsun, Turkey. Plant Disease, v. 87, p. 341-344, 2003.

SHANMUGASUNDARAM, S.; ISHII, M.; GILBERT, J.C.; NAGAI, H. Cucurbit virus studies in Hawaii. Plant Disease Reporter, v. 53, p. 70-74, 1969.

SILBERSHIMIDT, K.; NOBREGA, N.R. Uma doença de vírus de bananeira. O Biológico, v. 7, p. 216-219, 1941.

STANGARLIN, O.S.; DIAS, P.R.P.; REZENDE, J.A.M. Levantamento das viroses em cucurbitáceas no Estado do Mato Grosso do Sul, Brasil. Summa Phytopathologica, v. 26, p. 132, 2000 /resumo/.

STANGARLIN, O.S.; DIAS, P.R.P.; BURIOLLA, J.E.; REZENDE, J.A.M. Incidência de viroses em ensaios de avaliações de genótipos de abóboras e de pepino na região de Dourados/MS. Fitopatologia Brasileira, v. 26, p.532, 2001 /resumo/.

THORNBURY, D.W.; PIRONE, T. P. Helper components of two potyviruses are serologically distinct. Virology, v. 125, p. 487-490, 1983.

ULLMAN, D.E.; CHO, J.J.; GERMAN, T.L. Occurrence and distribution of cucurbit viruses in the hawaiian islands. Plant Disease, v. 75, p. 367-370, 1991. 
UMESH, K.C.; VALENCIA, J.; GUBLER, W.D.; FALK, B.W. The incidence of aphids and aphid-transmitted viruses in melo cultivars and breeding lines in California. Phytopathology, v. 85, p. 1042, 1995.

VEGA, J.; REZENDE, J.A.M.; YUKI, V.A Detecção do vírus do mosaico amarelo da abobrinha-de-moita no Brasil: caracterização parcial de um isolado encontrado em São Paulo. Fitopatologia Brasileira, v. 20, p. 72-79, 1995.

VEGA, J.; REZENDE, J.A.M.; YUKI, V.A.; NAGAI, H. Constatação do vírus do mosaico amarelo da abobrinha-de-moita ("zucchini yellow mosaic virus") no Brasil, através de MEIAD e ELISA. Fitopatologia Brasileira, v. 17, p. 118, 1992 /resumo/.

YUAN, C.; ULLMAN, D.E. Comparison of efficiency and propensity as measures of vector importance in Zucchini yellow mosaic potyvirus transmission by Aphis gossypii and A. craccivora. Phytopathology, v. 86, p. 698-703, 1996.

YUKI, V.A. Epidemiologia e controle do mosaico (VMM-Me) em abobrinha-demoita. Piracicaba, 1990. 84 p. Tese (Doutorado) - Escola Superior de Agricultura "Luiz de Queiroz", Universidade de São Paulo.

YUKI, V.A.; REZENDE, J.A.M.; KITAJIMA, E.W.; BARROSO, P.A.V.; KUNIYUKI, H.; GROPPO, G.A.; PAVAN, M.A. Occurence, distribution and relative incidence of five viruses infecting cucurbits in the State of São Paulo, Brazil. Plant Disease, v. 84, p. 516-520, 2000. 
APÊNDICES 


\section{APÊNDICE 1}

Resultados de três experimentos sobre a interferência do Papaya ringspot virus Type W (PRSV-W) na eficiência de transmissão do Cucumber mosaic virus (CMV) por duas espécies de afídeos em abobrinha de abobrinha de moita.

\section{Experimento 1 \\ Experimento 2 \\ Experimento 3}

$\mathrm{n}^{0}$ de pl. inoc. $/ \mathrm{n}^{0}$ de pl. infectadas** $\mathrm{n}^{0}$ de pl. inoc. $/ \mathrm{n}^{0}$ de pl. infectadas $\mathrm{n}^{0}$ de pl. inoc. $/ \mathrm{n}^{0}$ de pl. infectadas

Tratamento

CMV PRSV-W CMV+PRSV-W CMV PRSV-W CMV+PRSV-W CMV PRSV-W CMV+PRSV-W

$\begin{array}{lll}\text { CMV }^{*} & 9 / 1 & 9 / 0 \\ \text { PRSV-W } & 9 / 0 & 9 / 7 \\ \text { CMV+ PRSV-W } & 9 / 1 & 9 / 8 \\ \text { CMV } \rightarrow \text { PRSV-W } & 9 / 1 & 9 / 7 \\ \text { PRSV-W } \rightarrow \text { CMV } & 9 / 4 & 9 / 1\end{array}$

\section{$9 / 0$}

$9 / 0$

$9 / 1$

$9 / 1$

$9 / 1$

$9 / 0$

CMV

PRSV-W

$9 / 3 \quad 9 / 0$

CMV+ PRSV-W $\quad 9 / 2 \quad 9 / 6$

$\mathrm{CMV} \rightarrow \mathrm{PRSV}-\mathrm{W} \quad$ 9/2 $\quad 9 / 5$

PRSV-W $\rightarrow$ CMV $\quad 9 / 0 \quad 9 / 8$

Aphis gossypii

$\begin{array}{cccccc}9 / 6 & 9 / 0 & 9 / 0 & 6 / 6 & 6 / 0 & 6 / 0 \\ 9 / 0 & 9 / 9 & 9 / 0 & 6 / 0 & 6 / 6 & 6 / 0 \\ 9 / 1 & 9 / 5 & 9 / 0 & 6 / 6 & 6 / 1 & 6 / 1 \\ 9 / 5 & 9 / 5 & 9 / 4 & 6 / 1 & 6 / 0 & 6 / 0 \\ 9 / 2 & 9 / 8 & 9 / 2 & 6 / 3 & 6 / 0 & 6 / 0 \\ & \text { Myzus persicae } & & & & \\ 9 / 6 & 9 / 0 & 9 / 0 & 6 / 0 & 6 / 0 & 6 / 0 \\ 9 / 0 & 9 / 9 & 9 / 0 & 6 / 0 & 6 / 4 & 6 / 0 \\ 9 / 1 & 9 / 5 & 9 / 0 & 6 / 1 & 6 / 6 & 6 / 1 \\ 9 / 3 & 9 / 8 & 9 / 2 & 6 / 0 & 6 / 4 & 6 / 0 \\ 9 / 4 & 9 / 5 & 9 / 4 & 6 / 0 & 6 / 2 & 6 / 0\end{array}$

*CMV: plantas inoculadas com afídeos que adquiriram somente o CMV; PRSV-W: plantas inoculadas com afídeos que adquiriram somente o PRSV-W; CMV+PRSV-W: plantas inoculadas com afídeos que adquiriram simultaneamente o CMV e o PRSV-W; CMV $\rightarrow$ PRSV-W: plantas inoculadas com afídeos que adquiriram o CMV seguido do PRSV-W; PRSVW $\rightarrow$ CMV: plantas inoculadas com afídeos que adquiriram o PRSV-W seguido do CMV. ${ }^{* *}$ Números de plantas inoculadas/número de plantas infectadas. ${ }^{\star \star \star ~ I n f e c c ̧ a ̃ o ~ m i s t a . ~}$ 


\section{APÊNDICE 2}

Resultados de três experimentos sobre a interferência do Zucchini yellow mosaic virus (ZYMV) na eficiência de transmissão do Cucumber mosaic virus (CMV) por duas espécies de afídeos em abobrinha de moita.

Experimento 1

Experimento 2

Experimento 3

$\mathrm{n}^{0}$ de pl. inoc./ $\mathrm{n}^{0}$ de pl. infectadas** $\mathrm{n}^{0}$ de pl. inoc./ $\mathrm{n}^{0}$ de pl. infectadas $\mathrm{n}^{0}$ de pl. inoc. $/ \mathrm{n}^{0}$ de pl. infectadas

Tratamento

CMV ZYMV

CMV+ZYMV

CMV ZYMV

CMV+ZYMV

$\begin{array}{lll}\mathrm{CMV}^{*} & 9 / 5 & 9 / 0 \\ \text { PRSV-W } & 9 / 0 & 9 / 4 \\ \text { CMV+ PRSV-W } & 9 / 2 & 9 / 3 \\ \text { CMV } \rightarrow \text { ZYMV } & 9 / 1 & 9 / 3 \\ \text { ZYMV } \rightarrow \text { CMV } & 9 / 8 & 9 / 0\end{array}$

$$
9 / 0
$$

$\begin{array}{ll}9 / 3 & 9 / 0 \\ 9 / 0 & 9 / 3 \\ 9 / 6 & 9 / 1 \\ 9 / 2 & 9 / 1 \\ 9 / 1 & 9 / 0\end{array}$

Aphis gossypii

Myzus persicae

\begin{tabular}{|c|c|c|c|c|c|c|c|c|c|}
\hline CMV & $9 / 1$ & $9 / 0$ & $9 / 0$ & $9 / 1$ & $9 / 0$ & $9 / 0$ & $6 / 0$ & $6 / 0$ & $6 / 0$ \\
\hline ZYMV & $9 / 0$ & $9 / 6$ & $9 / 0$ & $9 / 0$ & $9 / 4$ & $9 / 0$ & $6 / 0$ & $6 / 6$ & $6 / 0$ \\
\hline $\mathrm{CMV}+\mathrm{ZYMV}$ & $9 / 1$ & $9 / 4$ & $9 / 1$ & $9 / 3$ & $9 / 5$ & $9 / 1$ & $6 / 3$ & $6 / 1$ & $6 / 0$ \\
\hline $\mathrm{CMV} \rightarrow \mathrm{ZYMV}$ & $9 / 1$ & $9 / 5$ & $9 / 1$ & $9 / 3$ & $9 / 4$ & $9 / 1$ & $6 / 0$ & $6 / 2$ & $6 / 0$ \\
\hline $\mathrm{ZYMV} \rightarrow \mathrm{CMV}$ & $9 / 2$ & $9 / 4$ & $9 / 1$ & $9 / 0$ & $9 / 2$ & $9 / 0$ & $6 / 0$ & $6 / 0$ & $6 / 0$ \\
\hline
\end{tabular}

${ }^{*} \mathrm{CMV}$ : plantas inoculadas com afídeos que adquiriram somente o CMV; ZYMV: plantas inoculadas com afídeos que adquiriram somente o ZYMV; CMV+ZYMV: plantas inoculadas com afídeos que adquiriram simultaneamente o CMV e o ZYMV; CMV $\rightarrow Z Y M V$ : plantas inoculadas com afídeos que adquiriram o $C M V$ seguido do ZYMV; ZYMV $\rightarrow C M V$ : plantas inoculadas com afídeos que adquiriram o ZYMV seguido do CMV. ${ }^{* *}$ Números de plantas inoculadas/número de plantas infectadas. *** Infecção mista. 